\title{
Promoting Respectful Maternity Care: A training guide for community-based workshops-Community facilitator's guide
}

Charity Ndwiga

Population Council

Charlotte E. Warren

Population Council

Timothy Abuya

Population Council

Lucy Kanya

Alice Maranga

See next page for additional authors

Follow this and additional works at: https://knowledgecommons.popcouncil.org/departments_sbsr-rh

Part of the Demography, Population, and Ecology Commons, Family, Life Course, and Society

Commons, International Public Health Commons, Maternal and Child Health Commons, and the Women's Health Commons

How does access to this work benefit you? Let us know!

\section{Recommended Citation}

Ndwiga, Charity, Charlotte E. Warren, Timothy Abuya, Lucy Kanya, Alice Maranga, Christine Ochieng, Mary Wanjala, Beatrice Chelang'at, Anne Njeru, Annie Gituto, George Odhiambo, Faith Mbehero, Lucia Maina, and Jeremiah Maina. 2014. "Promoting Respectful Maternity Care: A training guide for community-based workshops-Community facilitator's guide." New York: Population Council. 


\section{Authors}

Charity Ndwiga, Charlotte E. Warren, Timothy Abuya, Lucy Kanya, Alice Maranga, Christine Ochieng, Mary Wanjala, Beatrice Chelang'at, Anne Njeru, Annie Gituto, George Odhiambo, Faith Mbehero, Lucia Maina, and Jeremiah Maina 


\section{COMMUNITY FACILITATOR'S GUIDE}

\section{PROMOTING}

\section{RESPECTFUL}

MATERNITY CARE

\section{A TRAINING GUIDE FOR COMMUNITY- BASED WORKSHOPS}


Translating Research into Action, TRAction, is funded by United States Agency for International Development (USAID) under Cooperative Agreement No. GHS-A-00-09-00015-00. The project team includes prime recipient, University Research Co., LLC (URC), Harvard University School of Public Health (HSPH), and sub-recipient research organizations.

This toolkit is made possible by the support of the American People through the Unites States Agency for International Development (USAID). The contents of this report are the sole responsibility of Population Council and the Heshima Project and do not necessarily reflect the views of USAID or the United States government.

\section{POPULATION COUNCIL \\ Ideas. Evidence. Impact.}

The Population Council confronts critical health and development issues-from stopping the spread of HIV to improving reproductive health and ensuring that young people lead full and productive lives. Through biomedical, social science, and public health research in 50 countries, we work with our partners to deliver solutions that lead to more effective policies, programs, and technologies that improve lives around the world. Established in 1952 and headquartered in New York, the Council is a nongovernmental, nonprofit organization governed by an international board of trustees.

Population Council

General Accident Insurance House

Ralph Bunche Road, PO Box 17643 - 00500

Nairobi, Kenya

Suggested Citation: Ndwiga,Charity, Charlotte Warren, Timothy Abuya, Lucy Kanya, Alice Maranga, Christine Ochieng, Mary Wanjala, Beatrice Chelang'at, Anne Njeru, Annie Gituto, George Odhiambo, Faith Mbehero, Lucia and Jeremiah Maina. 2014. Respectful Maternity Care Resource Package; Community Facilitator's Guide, New York, Population Council.

Note: This publication is part of a larger publication entitled Respectful Maternity Care Resource Package. This document is intended to support Facilitators in leading RMC workshops at the facility and the community levels.

This Resource Package includes the following:

$\checkmark$ Facilitator's guide (Facility-based workshops)

$\checkmark$ Facilitator's guide (Community-based workshops)

$\checkmark$ Participant's manual

$\checkmark$ Community flipchart

$\checkmark$ Tools

$\checkmark$ Program briefs

For more information or clarification on any of the above materials, please contact the Population Council at publications@popcouncil.org. 


\section{Acknowledgements}

This Community Facilitators Manual is part of the RMC Resource Package developed by the Population Council in conjunction with the National Nurse Association of Kenya (NNAK) and the Kenya Federation of Women Lawyers (FIDA) under the Heshima Project.

The Resource Package was developed and tested as part of an implementation research study conducted in Kenya by the Population Council as part of the TRAction project under USAID Cooperative Agreement No. GHS-A-00-09-00015-00.

The research would not have been possible without invaluable support from the policymakers, health managers, service providers, and communities in five counties in Kenya. The authors wish to thank the Reproductive and Maternal Health Services Unit, and Nursing Services Unit, the Ministry of Health in Kenya, the Nursing Council of Kenya and the Heshima Project Steering Committee for their input. We are also grateful for the support of USAID/Kenya, and would like to thank all of the Respectful Maternity Care champions at global and national levels for their support during the entire project period. 


\section{Table of contents}

Acknowledgements i

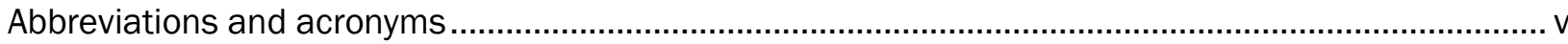

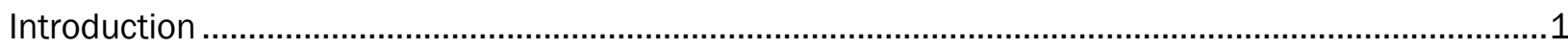

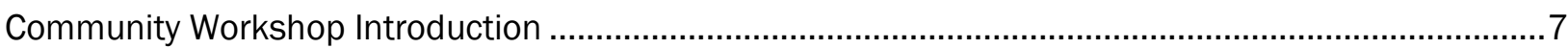

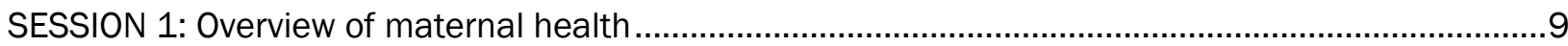

SESSION 2: Gender Dynamics in Respectful Maternity Care ....................................................... 13

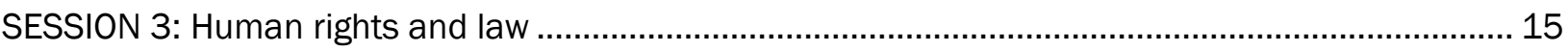

SESSION 4: Disrespect and abuse of women during facility-based childbirth ................................. 17

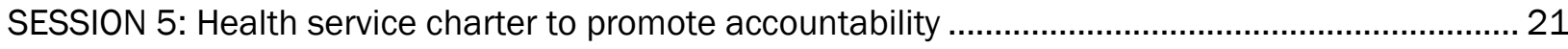

SESSION 6: Mediation as an alternative dispute resolution mechanism ......................................... 26

SESSION 7: Community's role in promoting respectful and dignified childbirth ............................... 33

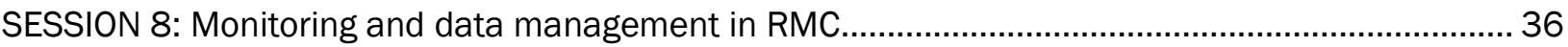

SESSION 9: Develop action plans for sensitizing community members .......................................... 38

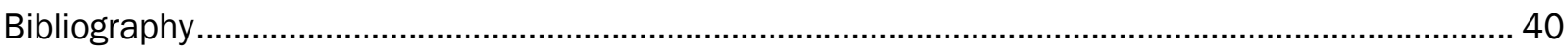

Appendix 1: Community TOTs Workshop Schedule ........................................................................ 42

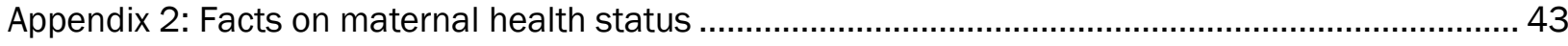

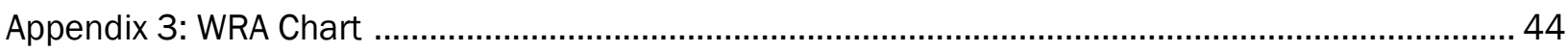

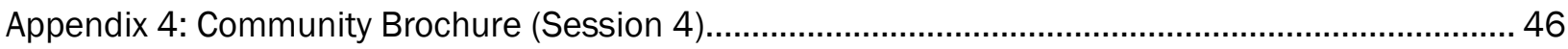

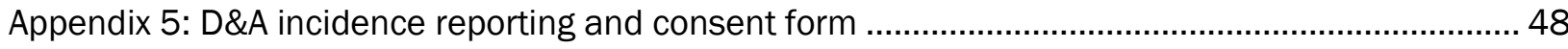

Appendix 6: Monthly monitoring data form for community health workers (CHWs) and community

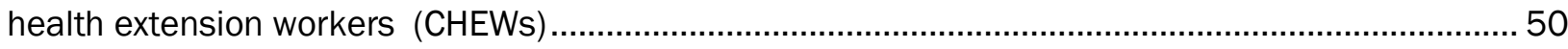

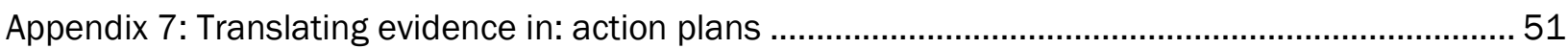




\section{Abbreviations and acronyms}

\begin{tabular}{|c|c|}
\hline ADR & Alternative Dispute Resolution \\
\hline CHEWs & Community Health extension workers \\
\hline CHWs & Community Health Workers \\
\hline CQITs & Continuous Quality Improvement Teams \\
\hline D\&A & Disrespect and Abuse \\
\hline DMHT & District Health Management Team \\
\hline FIDA-Kenya & Federation of Women Lawyers Kenya \\
\hline HFMC/B & Health Facility Management Committees or Boards \\
\hline ICM & International Confederation of Midwives \\
\hline ICN & International Council of Nurses \\
\hline MDG & Millennium Development Goal \\
\hline $\mathrm{MOH}$ & Ministry of Health \\
\hline NNAK & National Nurses Association of Kenya \\
\hline QITs & Quality Improvement Teams \\
\hline RMC & Respectful Maternity Care \\
\hline SBA & Skilled Birth Attendant \\
\hline TRAction & Translating Research into Action \\
\hline URC & University Research Co., LLC \\
\hline USAID & United States Agency for International Development \\
\hline VCAT & Values Clarification and Attitude Transformation \\
\hline VE & Vaginal Examination \\
\hline WRA & White Ribbon Alliance \\
\hline
\end{tabular}




\section{Introduction}

Pregnancy, childbirth, and their consequences are still the leading causes of death, disease, and disability among women of reproductive age in developing countries. Nearly 275,000 maternal deaths due to treatable conditions during pregnancy and childbirth occurred globally in 2011. Almost all of these took place in developing countries. ${ }^{1}$ Maternal mortality is highest in subSaharan Africa, where the maternal mortality ratio (MMR) is 100 times greater than in developed regions. A key strategy to address high maternal and newborn morbidity and mortality is to increase the proportion of births attended by skilled birth attendants (SBAs), a target of the maternal health Millennium Development Goal (MDG 5).

Progress toward achieving MDG 5 has been slow because improvements require overcoming financial and geographical barriers to accessing skilled care, as well as the poor quality of care in maternity units. A little understood component of the poor quality of care experienced by women during facility-based childbirth is the disrespectful and abusive (D\&A) behavior of health care providers and other facility staff. Acknowledgment of these behaviors by policymakers, program staff, civil society groups, and community members indicates the problem is widespread.

In a landscape analysis conducted in 2010 , these behaviors were categorized into seven manifestations:

- Physical abuse

- Non-consented care

- Non-confidential care

- Non-dignified care

- Discrimination

- Abandonment of care

- Detention in facilities ${ }^{2}$

Numerous factors contribute to this experience, which are grouped into:

- Individual and community-level factors

- Normalizing D\&A

- Lack of legal and ethical foundations to address D\&A

- Lack of leadership in this area

- Lack of standards and accountability

- Provider prejudice due to lack of training and resources

As part of the USAID Translating Research into Action (TRAction) project, the Heshima Project in Kenya was tasked to: determine the manifestations, types, and prevalence of D\&A in childbirth; identify and explore the potential drivers of D\&A; and design, implement, monitor, and evaluate the impact of interventions for reducing D\&A including generating lessons for scale up. The interventions aimed to improve accountability of health providers at all levels of the health care system: policy, health program managers, facility or provider and community levels. This Resource Package is based on the most effective interventions, and provides practical, low cost,

\footnotetext{
1 Lozano R, Wang H, Foreman KJ, et al. 2011. "Progress towards Millennium Development Goals 4 and 5 on maternal and child mortality: An updated systematic analysis." Lancet 378: 1139-1165.

${ }^{2}$ Bowser L. and Hill K. 2010. "Exploring evidence for disrespect and abuse in facility-based childbirth: Report of a landscape analysis." Washington, DC: USAID.
} 
and easily adaptable strategies for facilities to improve respectful maternity care (RMC). RMC refers to the humane and dignified treatment of a childbearing woman throughout her pregnancy, birth, and the period following childbirth. It respects her rights and choices through supportive communication, actions, and attitudes. Because disrespectful and abusive behaviors and environments degrade the quality of maternity care, identifying and addressing D\&A is an important component of cultivating RMC in health facilities. The Resource Package is designed to support health facility managers, health care providers, and communities to confront disrespect and abuse during facility-based childbirth and to promote respectful maternity care.

\section{Why focus on preventing disrespect and abuse during childbirth?}

The Heshima Project baseline survey in Kenya revealed several facts that emphasize that disrespect and abuse is a pressing problem in Kenyan facilities, including:

- One out of five postpartum women leaving the postnatal ward reported feeling humiliated at some point during their most recent delivery in one of the 13 participating health facilities

- Nine out of ten health care providers said they had heard of or witnessed colleagues treating women inhumanely

- The majority of facilities do have most of the essential equipment and supplies needed to support women in childbirth

- The poorest women were not physically abused or asked for a bribe, but they were more likely to be abandoned

- Women under 19 years of age were more likely to experience non-confidential care compared to those between 20 and 29 years of age

- Women of higher parity (with one to three children) were more likely to be detained for nonpayment or bribes compared to those who had just given birth to their first child

- Married clients were less likely to be detained for nonpayment or bribes, but more likely to be neglected

- Clients with support from a partner or companion during delivery were less likely to experience inappropriate demands or detention for nonpayment

These facts all reveal an unacceptably high degree of D\&A occurring in a variety of ways in Kenyan facilities.

\section{About the Resource Package}

This set of resources is designed to be used by program managers, supervisors, trainers, technical advisors, and others who organize or facilitate RMC training workshops in the field of sexual and reproductive health, as well as skills updates in emergency obstetric and newborn care training. It provides experienced facilitators with the background information, materials, instructions, and tips necessary to effectively deliver a package of interventions to promote respectful care in the provision of reproductive, maternal, and newborn health services at both the facility and community levels.

This Resource Package includes activities and materials that advance a specific agenda: to promote increased support, advocacy, and provision of high-quality, woman-centered maternity care. These changes are not likely to occur immediately after one workshop; they may be incremental. It takes a hands-on approach to empower service providers, community health 
workers, communities, and policymakers with the knowledge and skills to tackle disrespect and abuse during childbirth.

\section{How should respectful maternity care training be implemented?}

Facilitators can offer a stand-alone Respectful Maternity Care Workshop at health facilities and at community level. They may incorporate a selection of activities for ongoing training updates or interventions on maternal and newborn care. Trainers are encouraged to adapt the exercises or include other exercises helpful for promoting respectful maternity care. We suggest starting with stand-alone workshops. Then, once a core team of facilitators exists at the county/district/regional level, incorporate content into other meetings, workshops, or continuing professional development sessions. Be sure to allow sufficient time for discussion or role plays.

Workshops are designed to be offered as follows:

- $\quad$ RMC orientation workshop (two days): For policymakers, health managers, legal and health rights advocates, and media professionals. This workshop is intended to orient individuals about RMC who are not themselves medical service providers but who still influence the dynamic and quality of care that women receive. The workshop includes materials and intervention activities that highlight key practical points for promoting RMC. All sessions in the Facilitator's Guide are covered, but in a much shorter version and level of detail than in the workshop for service providers. PowerPoint presentations, program briefs, and other instructional resources are available. (Note: a full two-day session allows for more discussion and reflection.)

- Facility-based workshop for service providers (three days): For maternity unit employees at health facilities. This workshop builds a team of individuals at a facility who understand the issues surrounding D\&A and who can act as advocates of respectful maternity care. Those who are identified as good potential facilitators should also attend this workshop for more in-depth understanding of the issues. A Facilitator's guide (for Facility-based workshops) and Participants manual supports the training of health care providers.

- Community-based workshop (one day): for community health workers (CHWs) or volunteers, society leaders, and health and civil rights watch group representatives. The content can be delivered in a one-day workshop and includes information on the rights and obligations of women who give birth in facilities and of service providers as well as how to conduct alternative dispute resolution sessions (see schedule in Appendix 1). 


\section{What is included in the Resource Package?}

1. Facilitator's guide (for facility-based workshops): This guide assists facilitators (who can be service providers, health managers, community health workers, legal professionals, etc.) in leading facilitybased training workshops on improving respectful maternity care. The Guide integrates Values Clarification and Attitude Transformation (VCAT) training into a set of interventions that promote respectful maternity care. VCAT training is designed to help participants explore, question, clarify, and affirm their values and beliefs about D\&A during childbirth and related sexual and reproductive health (SRH) services to increase their awareness of and comfort in providing respectful care. The guide includes activities and materials (e.g., role plays and discussion questions) that promote the following values: increased support of childbearing women; advocacy for and provision of high-quality, womancentered maternity care; and the rights of clients. PowerPoint presentations are available.

2. Participant's guide: This manual is used by the participants as a reference tool it includes participant learning activities and exercises.

3. Facilitator's guide (for community-based workshops): This manual is designed to be used by facilitators to promote respectful maternity care at a community level. The manual can be adapted to educate a variety of stakeholders in community settings (i.e., Community Health Extension Workers, Community Health Workers, society leaders, legal aid officers, etc.). It highlights key practical points to enable participants to act as resource persons regarding the rights and obligations of childbearing women, and as advocates of respectful maternity care including how to conduct an alternative dispute resolution mechanism.

4. Community flipchart: This is a teaching aid for CHWs and other community-level resource persons to conduct community sensitization meetings or training workshops for general community members. The content and language used in the flipchart is simple and pictorial. Brochures are available for participants to take home as resources.

5. Tools: These offer guidance for conducting or organizing evidence-based interventions that promote respectful maternity care. These tools support:

- Maternity Open Days: A day set aside by a health facility that permits community members to visit the maternity ward and interact with maternity staff in order to demystify myths and misconceptions surrounding facility-based childbirth.

- Alternative Dispute Resolution (ADR): Mediation is a cost-effective conflict resolution mechanism that brings clients or relatives affected by D\&A and the perpetrators together to discuss and resolve issues without the need for formal legal measures.

- "Caring for the carers" counseling sessions: Counseling sessions for service providers and other staff working in maternity units/wards, or the facility as whole, help them cope with work-related psychological stress or trauma, which is a major driver of D\&A.

\section{Reference materials:}

- Research Briefs: describing evidence-based methods to reduce D\&A at all levels.

- Links to other websites/resources:

- Universal Rights of Childbearing Women Charter, Respectful Maternity Care Brochure, Respectful Maternity Care: refer to the following webpage: http://whiteribbonalliance.org/campaigns/respectful-maternity-care/

- Professional codes of ethics from FIGO, ICM, ICN

- RMC on K4Health

All Resource Package materials are available on a CD-ROM or from the Population Council website at www.popcouncil.org. 


\section{Who should use this Resource Package?}

This Resource Package is designed to be adaptable for a variety of stakeholders in different settings that include: health care professionals, policymakers, legal professionals, community health workers, lay community members, advocacy groups, and maternal health program implementers. Childbirth beliefs and behaviors tend to be context-specific and are founded on a myriad of social, cultural, professional and political factors. The activities in this Resource Package may be adapted to different social contexts.

\section{Who should use the community facilitator's guide?}

Reproductive health trainers, health care managers, supervisors, program managers or anyone responsible for training community-level workers or volunteers, society leaders and legal aid officers can use the “Promoting Respectful Maternity Care; Community Facilitator's Guide." It highlights key practical points that can be used by community-level resource persons and advocates in promoting women and families' understanding of their rights and obligations regarding dignified childbirth. It is specifically designed to help community members to proactively engage with health providers, health managers, and policy makers in promoting respectful maternity care. However facilitators should be very familiar with all of the components of the Resource Package.

Some community facilitators may choose these contents for a stand-alone training on promoting respectful maternity care at community level, while others may incorporate a selection of activities into any national $\mathrm{CHWs}$ training manual, other community level meetings, or special event such as community dialogue days. After the training, the participants will work in collaboration with Community Focal Persons or Community Health Extension Workers (CHEWs) to conduct community-level sensitization meetings/trainings on the respectful maternity care concept and other activities aimed at promoting RMC. To support these activities, the community flipchart and tools and any other reference materials can be used.

\section{Tips for facilitators}

\section{Characteristics of effective training}

This Resource Package is designed on adult learning principles for a learner-centered, interactive training approach. Facilitators are encouraged to model the concepts and skills needed for effective training, including group facilitation, coaching, and non-judgmental conduct. All effective training courses or workshops share should take into consideration the following:

- Trainers and participants should understand the purpose of the training

- Trainers and participants should understand the objectives of the workshop

- Training methods should enable participants to achieve the objectives of the training

- Training should build on participants' existing skills and experience

- Use open-ended questions that begin "how", "what" "when", and "why" to invite discussion and feedback

- New knowledge and skills should be presented in a meaningful and relative context

- Use a variety of training methods to meet the needs of different learning styles 
- Create opportunities for participants to apply new knowledge and skills

- Provide constructive feedback for participants on their performance

- Ensure enough time for participants to meet the objectives of the training

- Trainers should solicit and accept feedback from participants and use this feedback to make improvements in the training

REMEMBER: Effective training techniques keep participants engaged in the learning process, help trainers to assess how the training is being received, and help trainers adjust the training process as needed.

\section{Participant selection}

Facilitators are encouraged to carefully consider how participants' backgrounds and characteristics will affect the experience and the effectiveness of the workshop. It is important for participants to feel safe and comfortable engaging in an honest examination and exploration of their beliefs, opinions and attitudes, and to remain open to change. Whenever possible, we recommend assessing participants' knowledge, attitudes and practices with regard to respectful maternity care in advance to aid in participant selection and workshop design.

It is the responsibility of the facilitator to create and maintain an open learning environment. Different viewpoints about childbirth and the issue of D\&A are valid, inevitable and will contribute to the richness of group discussion. There are benefits and risks to mixing participants with different personal and professional backgrounds, experiences of supporting women in the community and viewpoints about women's rights and choice of where to give birth. In different circumstances, a more diverse group can increase the amount of facilitation needed.

The optimum facilitator-to-participant ratio is 1:7. Important workshop materials include:

- PPT presentations and projector

- Flipchart paper

- Markers
- Cards/sticky notes

- Masking tape

- Note books and pens

- Reference materials

\section{Teaching methods}

As with any training event, workshops should utilize adult learning principles. The following are commonly used teaching methods:

- Interactive presentations

- Large and small group discussions

- Individual and group work

- Hypothetical and real case studies

- Sensitivity and listening techniques
- Expressive activities (role play, songs, skits, artwork, games)

- Simulations

- Personal journals and interviews

- Self-analysis worksheets

\section{Additional background content}

We recommend background sessions on topics related to respectful and dignified maternity care. These may include:

- Data on maternal and newborn mortality and morbidity on regional, national, and global scales

- Context-specific data on the proportion of women who attend antenatal services, facilitybased childbirth, and postnatal care services where available 
- Overviews of international meetings, treaties, and agreements that support human rights and rights-based approaches to care

- Context-specific data on manifestation of disrespect and abuse (from DHS or other sources)

- Context-specific data on the drivers of disrespect and abuse from service provision surveys, WHO, or other relevant sources

- Relevant context-specific data on the magnitude and prevalence of disrespect and abuse (if available).

\section{Community Workshop Introduction}

\section{Overall workshop objectives}

By the end of the workshop, the participants will be able to:

1. Outline the current status of maternal health in relation to respectful maternity care

2. Discuss rights-based approaches related to RMC

3. Discuss selected strategies that reduce disrespect and abuse

4. Discuss the role of the community in promoting respectful maternity care

5. Demonstrate knowledge and use of alternative dispute resolution mechanism

6. Develop action plans to support the implementation of RMC interventions at the community level. 


\section{WORKSHOP INTRODUCTION}

\begin{tabular}{|c|c|c|}
\hline $\begin{array}{l}\text { Learning objectives } \\
\text { By the end of the session the } \\
\text { participants will be able to: } \\
\text { 1. Articulate their hopes and } \\
\text { concerns about the } \\
\text { workshop and about the } \\
\text { topic of disrespect and } \\
\text { abuse. }\end{array}$ & $\begin{array}{l}\text { Training materials } \\
\text { - Index cards or paper } \\
\text { - Sticky note pads } \\
\text { - Pens or pencils } \\
\text { - Flipchart easel and paper }\end{array}$ & $\begin{array}{l}\text { Session length: } \\
15 \text { Minutes } \\
\text { - } 5 \text { minutes for writing on } \\
\text { cards/papers } \\
\text { - } 5 \text { minutes to discuss in } \\
\text { pairs } \\
\text { - } 5 \text { minutes to discuss } \\
\text { responses }\end{array}$ \\
\hline
\end{tabular}

Participants' Expectations and Group Norms

This is an introductory activity that can be completed as an icebreaker at the beginning of a workshop.

This activity helps participants identify their expectations and/ or concerns and discomforts regarding the workshop.

The same can be used at the end of the workshop to assess whether their expectations have been met as a result of the training.

\section{Participants will state/write:}

- Their expectation(s) for this workshop

- What they hope to accomplish during the workshop

- What they hope to accomplish by the end of this workshop

- Any suggestions on the group norms during the workshop 


\section{SESSION 1:}

\section{Overview of maternal health}

\section{Learning objectives}

By the end of the session the participants will be able to:

1. Briefly discuss the RMC concept.

2. Outline the current status of maternal and newborn health globally, regionally, and locally.

3. Discuss factors contributing to maternal mortality and morbidity.

4. Discuss the evidence for disrespect and abuse during facility-based childbirth.

\section{Training materials}

- Flipchart paper, markers, masking tape, sheets of paper or cards

- PPT presentation

- Chart of the global status on maternal health

- Reference materials on country's/region's status on maternal health.
Session length: 30 Minutes

\section{Facilitator's instructions}

- Introduce the session using a brain storming activity.

- Ask the participants to define or to explain the terms "respectful maternal care" and "maternal health".

- Write down all the responses on the flip chart.

- Summarize them and provide the correct definition using the PowerPoint presentation.

- Ask participants if they know of women who choose to deliver at home in their areas; ask for any recent (last 1 year) home deliveries.

- Ask participants to indicate the difference, in the terms of numbers, between those who deliver in health facilities and those who deliver at home; allow them to give reasons for answers provided.

- Summarize the responses on reasons mentioned and tell the participants that the workshop focuses on promoting respectful maternity care during childbirth.

- Use the PowerPoint presentation to discuss barriers to receiving quality maternal health care

- Use the PowerPoint slides to briefly discuss available evidence on disrespect and abuse from Population Council studies. 


\section{Content}

\section{Respectful Maternity Care Concept}

RMC involves respect for women's basic human rights including: respect for women's autonomy, dignity, feelings, choices, and preferences, including companionship during maternity care ${ }^{3}$

\section{Definition of Maternal Health}

Maternal health refers to the health of women during pregnancy, childbirth and the first few days and weeks after childbirth. While motherhood is often a positive, fulfilling experience, far too many women associate it with suffering, ill-health, and even death4.

Up to 287,000 women die each year during pregnancy and childbirth (globally). Most of them die because they had no access to skilled maternity care for either normal or complicated childbirth (WHO et al., 2012).

About 800 women die from preventable pregnancy or childbirthrelated complications around the world every day. Almost all maternal deaths ( 9 out of 10 women) occur in developing countries. More than half of these deaths occur in sub-Sahara Africa (SSA) and approximately one-third occurring in South Asia5,6 (see WHO Maternal Health Charts Appendix 2).

Brainstorming activity: Are you aware of any women who chose to give birth at home in your area in the last one year?

If yes, give a reason why you think might have led to their choice.

What do you think is the difference in the terms of numbers between those who deliver in health facilities and those who deliver at home?

Most maternal deaths are avoidable, as the health care solutions to prevent or manage complications are well known. All pregnant women need access to quality antenatal care, skilled care during childbirth, and care and support in the weeks after childbirth. They also need access to fully functioning emergency care when complications occur. It is critical that all births are attended by skilled health professionals who can provide competent life-saving interventions. Interventions need to focus on improving the quality of care. One key component of quality care is respectful maternity care $(\mathrm{RMC})^{7}$.

\footnotetext{
${ }^{3}$ WRA, 2011. Respectful Maternity Care Brochure, Respectful Maternity Care:http://whiteribbonalliance.org/campaigns/respectfulmaternity-care/

${ }^{4}$ WHO, UNICEF, UNFPA and The World Bank estimates. (2012).Trends in maternal mortality: 1990 to 2010. Department of Reproductive Health and Research, World Health Organization, Avenue Appia 20, CH-1211 Geneva 27, Switzerland

${ }^{5}$ WHO Infographic. 2014. "Saving Mothers Lives."

http://www.who.int/reproductivehealth/publications/monitoring/infographic/en/

${ }^{6}$ Trends in maternal mortality 1990 to 2013 WHO 2014

${ }^{7}$ WHO,USAID. "Every Newborn: An Action Plan to End Preventable Deaths." WHO Press: Geneva, 2014.
} 


\section{Who is a skilled health professional?}

A skilled health professional or skilled birth attendant (SBA) is a health professional such as a midwife, doctor or nurse - who has been educated and trained and has the skills required to manage:

- Normal, uncomplicated pregnancies

- Childbirth

- The immediate postnatal period

- Identification, management and referral of complications in women

- Identification, management and referral of complications in newborns" 8

Barriers to accessing / receiving quality maternal health care

- Perceived or real negative provider attitudes

- Poor quality of care reported in facilities during childbirth, including disrespectful and abusive treatment by health providers and facility staff

- Inadequate provision of the absolute minimum maternity care services

- Low levels of provider competency, skills and poor management of facilities

- Poor facility infrastructure, e.g. water, electricity, equipment, drugs, and supplies

Brainstorming activity:

If a woman wants to squat during childbirth, what happens in the facility?

What happens to a woman's placenta in the facility near you?

- Cost of services

- Cultural beliefs, stigma and the perception of both clients and providers on various health conditions and services

- Gender and the decision-making process

- Awareness of availability of services

- Actual availability, physical and social accessibility of services

- Poor access to facilities due to weak road network and other communication network

- Lack of available emergency transport

In addition to geographic, financial and cultural barriers, seven categories of disrespect and abuse have been identified: physical abuse, non-consented care, non-confidential care, non-dignified care, discrimination, abandonment of care, and detention in facilities or demand for payment ${ }^{9}$.

\footnotetext{
${ }^{8}$ WHO-ICM-FIGO Joint Statement 2004 NB “Midwife” definition

${ }^{9}$ Bowser and Hill 2010 Exploring evidence for disrespect and abuse in facility based childbirth: Report of a Landscape Analysis Bethesda, MD: USAIDTRAction Project, University Research Corporation, LLC, and Harvard School of Public Health
} 


\section{Evidence of disrespect and abuse during facility based childbirth}

A study conducted in Kenya ${ }^{10}$ to determine the prevalence of disrespect and abuse during childbirth showed that one in five women interviewed as they left the postnatal ward $(n=644)$ reported feeling humiliated at some point during labor and delivery experience across 13 Kenyan health facilities. The study also showed that $18 \%$ of these women experienced non-dignified care, 14\% neglect/abandonment, 9\% non-confidential care, $8 \%$ detention, $4 \%$ physical abuse, and $1 \%$ were asked for bribes during labor and the immediate post-natal period.

Nine out of ten health care providers said they had heard of or witnessed colleagues treating women inhumanely. Although lack of equipment and supplies is described as a driver of D\&A, the data found that facilities do in fact have most of the essential equipment and supplies needed to support women in childbirth; with a mean score of $31 / 35$ of essential equipment and supplies available for normal maternity services. The figure below identifies potential drivers of D\&A.

Figure 1: Drivers (root causes) of disrespect and abuse

\section{WHAT DRIVES DISRESPECT AND ABUSE?}

\begin{tabular}{|c|c|c|}
\hline $\begin{array}{l}\text { At policy and governance } \\
\text { levels: } \\
\text { - Non-realization of } \\
\text { international conventions } \\
\text { - Complacency of } \\
\text { policymakers } \\
\text { - Insufficient funding for } \\
\text { maternal health care }\end{array}$ & $\begin{array}{l}\text { At health facility and provider levels } \\
\text { - Lack of understanding of clients' rights } \\
\text { - Inadequate infrastructure leading to poor } \\
\text { working environment } \\
\text { - Staff shortages leading to high stress } \\
\text { - Poor supervision } \\
\text { - Lack of professional support } \\
\text { - Weak implementation of standards and } \\
\text { quality of care guidelines }\end{array}$ & $\begin{array}{l}\text { At the community level: } \\
\text { - Imbalanced power } \\
\text { dynamics } \\
\text { - Overly complex } \\
\text { mechanism for victims } \\
\text { who seek redress } \\
\text { - Lack of understanding } \\
\text { of women's health } \\
\text { rights }\end{array}$ \\
\hline
\end{tabular}

10 Population Council, Confronting Disrespect and Abuse during Childbirth in Kenya The Heshima Project: Project Brief January 2014 www.popcouncil.org 


\section{SESSION 2:}

\section{Gender Dynamics in Respectful Maternity Care}

\section{Learning objectives}

By the end of the session the participants will be able to:

1. Define the difference between gender and sex.

2. Describe the social construction of gender.

3. Describe the causes of gender-based violence and discrimination.

4. Describe the role of gender in disrespect and abuse during childbirth.

\section{Training materials}

- Flipchart paper, markers, masking tape, sheets of paper or cards
Session length:

30 Minutes

\section{Facilitator's instructions:}

- Ask the participants to define/ differentiate between the terms "gender" and "sex"

- Initiate a discussion on gender roles as defined by different communities.

- Write down all the responses on the flip chart

- Summarize them and provide the correct definition

- Facilitate a discussion on the impact of gender roles on women

\section{Content}

\section{Defining biological sex and gender roles}

Gender refers to the social attributes and opportunities associated with being male and female and the relationships between women and men and girls and boys, as well as the relations between women and those between men (UN Women, 2001). These roles change over time and vary across different communities. Sex is the biological or physical difference between women and men. This does not vary between different communities and cannot be changed (except by surgical intervention). ${ }^{11}$

For example, society has set standards for the behavior of men and women.

Discrimination against the girl-child starts at birth in some communities, as evidenced in the different ways the birth of either sex is marked. For example, among the Kikuyu

\footnotetext{
${ }^{11}$ Federation of Women Lawyers Police Training Manual 2007 (FIDA-K)
} 
community of Kenya, 5 ululations are made when a boy-child is made while only 3 are made when a girl-child is born.

Stereotyping of gender roles starts early in childhood. Girls are taught from a very early age that their role is to handle domestic chores. Boys are categorically socialized to distance themselves from "female chores". Chauvinistic attitudes are cultured from very early in life. The girl-child is overworked at home, carrying the burden of the household chores from a very early age, often acting as an 'assistant mother'.

Global statistics show that girls form the majority of school attendants in the early schooling years - between 4-8 years; with higher dropout rates compared to boys, observed in the higher schooling levels ${ }^{12}, 13$. In many traditional setups, girls are viewed as transient members of the family, i.e. they will leave the family and marry into another family. They are therefore seen as a non-benefit or a loss to the family in the future. This might explain why families make the decision not to invest in girls' long-term education.

\section{The impact of gender and sex roles on women}

Messages about women are often portrayed negatively, classifying women as the weaker sex and regarded as being inferior to men. Women are discriminated against and not treated with respect which contributes to their limited participation in leadership positions. This can lead to discrimination of women and non-respectful treatment of women.

12 Plan. 2007. Because I Am a Girl: State of the World's Girls. London. http://www.un.org/womenwatch/osagi/conceptsandefinitions.htm

13 Levine R., C.B. Lloyd, M. Greene, and C. Grown. 2008. Girls Count: A Global Investment \& Action Agenda. Reprint, 2009. Washington, D.C.: Center for Global Development 


\section{SESSION 3:}

\section{Human rights and law}

\section{Learning objectives}

By the end of the session the participants will be able to:

1. Explain the link between health and human rights.

2. Explain the meaning of rights-based approach in programming.

3. State the characteristics of human rights.

\section{Training materials}

- Flipchart paper, markers, masking tape, sheets of paper or cards

- PPT slides

\section{Facilitator's instructions}

- Introduce the session by asking participants to share their understanding of the concept of human rights.

- Guide participants in critiquing responses shared and correcting as appropriate.

- Use the PowerPoint presentations and/or flip chart to deliver the session content.

- Involve the participants through questions and answers as appropriate throughout the presentations

\section{Content}

Every person has the human right to health including safe childbirth.

The Universal Declaration of Human Rights Article 25 of 1948 states:

"Everyone has the right to a standard of living adequate for...health and wellbeing of himself and his family, including food, clothing, housing, medical care and the right to security in the event of...sickness, disability...motherhood and childhood are entitled to special care and assistance..." (UN, 1948)

However, the actual links between health and human rights have not been recognized and well understood in terms of concepts, policy, law, programs, institutional structures and service delivery to protect pregnant women.

"The enjoyment of the highest attainable standard of health is one of the fundamental rights of every human being without distinction of sex, gender, race, religion, political belief, economic, social and geographical location" (WHO, 1946) 


\section{What is a Rights-Based Approach?}

It identifies among others:

- Rights holders and their entitlements and;

- Corresponding duty-bearers and their obligations

Rights holders: Individuals and groups with valid claims

Duty-bearers: State and nonstate actors with obligations

(OHCHR, 2006)

- Duty-bearers to meet their obligations.

\section{Governments/States/ Non-state actors/Duty bearers have a legal obligation to}

- Respect rights -support the enjoyment of rights e.g., access to maternal health services during pregnancy, childbirth and after birth

- Protect rights - prevent violations of human rights by third parties e.g., individual citizens e.g., men who beat and abuse women, employees, health workers mishandling patients - treating them disrespectfully.

- Fulfill rights - take appropriate government measures toward the full realization of rights e.g., allocating resources for and setting in place quality health services

\section{Characteristics of Human Rights}

- Internationally guaranteed

- Legally protected

- Focus on dignity of human being

- Protect individuals and groups

- Oblige state and non- state actors (required to act on the rights)

- Cannot be waived/ taken away

- Equal and interdependent

- Universal

- Indivisible 


\section{SESSION 4:}

\section{Disrespect and abuse of women during facility-based}

\section{childbirth}

\section{Learning objectives}

By the end of the session the participants will be able to:

1. Describe the seven categories of disrespect and abuse during facility-based childbirth.

2. Explain the drivers of disrespect and abuse during facility-based childbirth.

3. Discuss communities' role in promoting respectful and dignified childbirth.

\section{Training materials}

- Flipchart paper, markers, masking tape, sheets of paper or cards

- Handouts from WRA/universal rights of childbearing women (Appendix 3)

- Community brochure example (appendix 4)

\section{Facilitator's instructions}

- Introduce the session by informing the participants that disrespect and abuse is a common experience in many contexts e.g., transport, industry, public offices.

- Invite the participants to give any personal experiences they may have had both in their social life and health care setting that they considered disrespectful or inhumane. The facilitator may also give his/her own personal experience.

- Explain that disrespect and abuse affects the individual at a personal level and their future behavior in terms of seeking the services/recommending services to others.

- Use the lecture method and PowerPoint presentations and/or flipchart to deliver the session content.

- Involve the participants through questions and answers as appropriate throughout the presentations.

\section{Content}

\section{Introduction}

We know that having access to good skilled care from a health professional can make the difference between a pregnant woman's life and death. However, many women do not give birth with professional assistance. There is evidence that disrespect and abuse (D\&A) during facility based childbirth deters women from seeking help when they are in labor. 


\section{Categories of disrespect and abuse}

Building on a landscape analysis of disrespect and abuse globally ${ }^{14}$ and following interviews with men and women in Kenya, the categories of D\&A include:

1. Non-confidential care:

Many people perceive non-confidential care as:

- Examination, delivery and treatment that require undressing without curtains or partitions

- Consultation conducted without privacy and

- Group counseling and discussions where women are required to give their personal information in public.

2. Non-dignified care:

Communities perceive non-dignified care as:

- Use of harsh words that suggest rudeness and disrespect

- Lack of assistance in carrying their baby to the postnatal ward after delivery

- Providers reprimanding the client if she calls for help

- Cleaners and other subordinate staff without midwifery skills assisting in delivery

- When women are asked to undress in front of all other women in the labor wards with no gowns provided

- Sharing beds with other women.

3. Non - consented care:

- Lack of information and/or explanation of the treatment and procedures that are required. This includes physical examination, vaginal examination, tubal ligation or taking of medication if the client or her relative is in a position to make sound judgment at the time.

4. Physical abuse:

- Both men and women feel that slapping, pushing and pinching is abusive.

5. Discrimination:

Community members feel that women who are at an increased risk of discrimination are those that:

- Have five or more children

- Forget to carry or lack the antenatal clinic card

- Are poor

- Are young women (teenage mothers)

- Are living with HIV

\footnotetext{
${ }^{14}$ Bowser. L and Hill. K., Exploring evidence for disrespect and abuse in facility-based childbirth: Report of a landscape analysis. . 2010, USAID
} 


\section{Detention:}

Although in many countries detaining women in hospital for lack of funds to pay for treatment is illegal, reports indicate that women are still detained and are subjected to abusive treatment such as:

- Working in the facilities (washing utensils, toilets and washroom)

- Provision of beds for the baby only and none for the mother

- Separation from their infants in which mothers are only allowed to breastfeed their babies at fixed times in the nursery

7. Abandonment/ Neglect:

Communities perceive their women have been abandoned when:

- Providers ignore the clients or fail to attend to the clients on time

- Providers lock themselves in offices and do not respond to calls for assistance

- There is no skilled personnel available and women have to wait a long time for services such as Cesarean section

- Where there is no assistance until complications develop

- Women are left to deliver alone

- Women in severe pain are not given pain relief

- Women end up giving birth on benches in admission rooms waiting for help.

\section{Drivers of disrespect and abuse}

The drivers of D\&A can be defined as the reasons that might explain why D\&A during childbirth occurs (but should not be used as excuses) and helps communities and health systems work out ways to resolve the issues.

\section{Health system factors}

- Inadequate infrastructure e.g., lack of beds, curtains and drugs at the facilities.

- Poor supervision and management of facilities; providers miss duties and grave misconduct goes without punishment

- Poor payment and high workload of providers; work related stress and burnout may lead the provider to vent out on the mothers and partners during childbirth

- Poor human resource management of existing staff High cost of reproductive health services forces women to deliver at facilities of poorer quality where women are prone to abuse and disrespect

- Inadequate communication and linkages between the health facility management, providers and community members on issues related to facilitybased childbirth.

Community-level factors

- Lack of a clear understanding of legal mechanisms by communities

- Perception among community members that legal mechanisms and processes are expensive

- Some forms of abuse have been normalized e.g., slapping 
- The abusive practices are viewed as part of the process of ensuring the safety of the mother and baby

- Communities prefer to seek services from providers of the same ethnic group due to socialization and culture

- Limited opportunities for communities to seek redress if women are unhappy with the treatment they received

\section{Personal factors}

- Gender imbalance in many communities, in which the man is the overall decision maker for choice of both the service provider and facility for childbirth, which may make women more likely to experience disrespect and abuse

- Inadequate knowledge of individual and communities' rights to quality care during facility-based childbirth

- The waiver system is perceived as a big favor by some women. When women use it they are compelled to accept the services offered without questioning

- Traditional beliefs, practices, customs and taboos make it difficult to discuss the issues around childbirth either with the health facility staff or any form of authority at the community level

- Low socio-economic status leads women to seek services in low-quality facilities where women are prone to disrespect and abuse 


\section{SESSION 5:}

\section{Health service charter to promote accountability}

\section{Learning objectives}

By the end of the session the participants will be able to:

1. State the elements of the health service charter.

2. Explain the customers' health rights.

3. Discuss the customers' obligations.

4. Discuss Maternity Open Days.

\section{Training materials}

- Flipchart paper, markers, masking tape, sheets of paper or cards
Session

length:

30 Minutes

\section{Facilitator's instructions}

- Divide the participants into groups of five each. Provide the participants with a flipchart and felt pen.

- Ask the participants to write down what they consider to be their rights and obligations in health care

- In plenary, ask the groups to present their deliberations.

- During presentations, invite the rest of the participants to review the points. Then, provide them the correct answers.

- Use a guided illustrative lecture to discuss the service charter, customer/ client rights and obligations in the service charter

- End the session with question and answers on their rights and obligation

\section{Content}

\section{A service charter}

A service charter is a simple public document which briefly and clearly states the standard and quality of service that any customer can expect from an organization within the context of its services. The charter is guided by the organizations' vision, mission, values, culture and ethical policies.

Where they exist, a Ministry of Health's ( $\mathrm{MOH}$ ) service charter usually outlines;

- Responsibilities or commitments of the $\mathrm{MOH}$

- Responsibilities of service providers

- Customers' rights and obligations 


\section{MOH Responsibilities/Commitments}

Ministries of health are committed to achieve goals for delivering health services:

- Equitable distribution of health services

- Timely provision of health care services

- Provision of quality services

- Customers' rights to information

- Courtesy and respect to customers

- Non-discrimination to customers

- Confidentiality of a client's information

- Privacy of customers' care and treatment

- Avoiding any corrupt practices and preferential treatment of clients

- Establishing customer care centers in all facilities

- Conducting regular customer surveys and publishing reports.

\section{Responsibilities of health service providers}

Examples of health service providers' responsibilities:

- Promotion of healthy lifestyles

- Regulation of provision of health services

- Prevention of diseases

- Protection of the public against harm

- Coordination and provision of health services

- Clients/patients on arrival at hospital served speedily and handled with respect

- Respond to enquiries, and correspondence promptly

- Acknowledge technical and complex enquiries within stipulated timelines

- Provide accessible and timely services to all

- Attend to clients or patients within stipulated timelines.

\section{Customers' Rights}

All customers have the right to:

- Optimum care by qualified health care providers

- Accurate information

- Timely service

- Choice of health care provider and service

- Protection from harm or injury within health care facility

- Privacy and confidentiality

- Be treated courteously and with dignity

- Continuity of care

- Personal/own opinion and to be heard

- Emergency treatment in any facility of choice

- Dignified death, preservation and disposal

- Participate in the planning and management of health care service 


\section{Customers' Obligations}

Obligations are things you must do for moral or legal reasons for your own benefit or others in the society:

- Engage in healthy lifestyle

- Seek treatment promptly

- Seek information on illness and treatment

- Comply with treatment and medical instructions

- Be courteous and respective to health care providers

- Help to combat corruption by reporting any corrupt practices and refrain from seeking preferential treatment

- Enquire about the related costs of treatment and/or rehabilitation and to agree on the mode of payment.

- Care for health records in his or her possession

- Respect the rights of other patients and health care providers

- Provide health care providers with relevant and accurate information for diagnosis, treatment, rehabilitation or counseling purposes

- A duty to protect and conserve health facilities

- Participate in the management of health care services

- Fostering partnership in service delivery

An example of how to foster partnership is outlined below.

\section{Maternity Open Days}

Many community members do not understand the events and procedures associated with facility-based childbirth. Lack of understanding leads to mistrust between care providers community members. It leads to fear of D\&A, myths, and misconceptions about the procedures required assisting women during childbirth. These negatively influence their decisions to seek care at a health facility.

\section{Why the Maternity Open Days?}

Maternity Open Days provide an opportunity for pregnant women and their families to interact with health care providers and visit the maternity unit to help quell any fears they may have about giving birth in a facility.

Maternity Open Days provide an opportunity to understand how communities and health facility staff can work out how to support each other and see how some challenges can be 
overcome. For example, if a facility does not have a good supply of water, the community may offer to support the facility by harvesting rain water.

Maternity Open Days aim to:

- Promote mutual understanding, accountability and respect among community members and service providers

- Improve knowledge and demystify procedures during labor, childbirth and the immediate postnatal period

\section{How to hold a Maternity Open Day}

This activity is usually conducted jointly with the health facility management, a community focal person and the CHEWs. The following needs to be done;

- Agree on a date for the Maternity Open Day with health facility managers and community leaders

- Send invitations through the existing community information systems

- Invite community members, pregnant women and their families to visit the maternity unit

- Arrange for simple refreshments to be made available (if possible)

- Before the maternity unit visit, explain about care and procedures during labor and delivery including the layout of the maternity unit. Describe the quality of care that clients can expect. Allow for discussion to dispel any misconceptions/rumors

- Groups of 5-8 community members will be allowed to tour at time to avoid congestion

Note: Do not disrupt care for women in the maternity unit.

- The privacy and confidentiality of mothers in labor must be respected-community members should follow the guidance of service providers during the tour

- After the tour, midwives and other health care providers engage the community members with a question-and-answer session on:

- Were their expectations met during the tour?

- Clarify any other information they may have

- Ask community members for recommendations, i.e., what contributions can the community members make towards improving the maternity unit for both the providers and the clients? 
- Encourage facility-based childbirth and male involvement/birth companions during pregnancy labor and delivery. Remind them about birth and complication readiness plans

Other curative or preventive maternal health services may be integrated into the day's activities, e.g., minor treatment of childhood illnesses, screening for cancer of the cervix or prostrate.

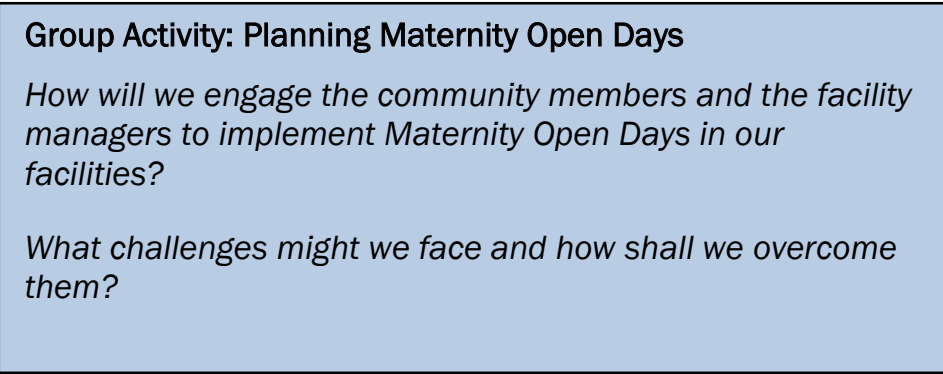




\section{SESSION 6:}

\section{Mediation as an alternative dispute resolution mechanism}

\section{Learning objectives}

By the end of the session the participants will be able to:

1. Define alternative dispute resolution (ADR) mechanism or mediation.

2. Discuss how mediation works.

3. Define a mediator.

4. Describe a mediator's role.

5. Discuss the mediation process in promoting respectful and dignified care during facility-based childbirth.

6. Discuss the advantages and disadvantages of mediation.

7. Demonstrate the use of mediation in resolving disrespect and abuse cases.

\section{Facilitator's instructions}

- Introduce the session by asking the participants to define "ADR" or "mediation". Write the responses down and discuss each option and provide the correct meaning.

- Use an illustrated lecture to deliver the session content.

- Conduct a role play to demonstrate the use of the mediation process to resolve D\&A

- Ask participants to volunteer for a demonstration

- Ask the participants to observe the roles and discuss them after the demonstration to reinforce learning.

\section{Content}

Definition of ADR mechanism: ADR is the use of the traditional or community justice systems in resolving conflict between parties. It is used strictly on a voluntary basis - no party should be forced into it. The ADR mechanism has been found to work to resolve conflict resulting from $D \& A^{15}$.

\footnotetext{
${ }^{15}$ Kariuki Muigua 2013. Heralding a New Dawn: Achieving Justice through effective application of Alternative Dispute Resolution Mechanisms (ADR) in Kenya" a Paper Presented at The Chartered Institute of Arbitrators (Kenya Branch) Annual Regional Conference held on 25th \& 26th July, 2013 at Nairobi
} 


\section{Definition of a mediator and mediator's role}

Mediator:

A mediator is a convener, an educator, reality tester, a guardian of the mediation process and an independent and impartial intervener. Mediators need to be specially trained 16 .

Mediator's role:

- Conflict assessor - he/she must attempt to understand as much of the conflict as possible

- Impartial convenor - by being neutrally involved in facilitating the negotiation processes

- Enhancing communication between the parties in dispute

- Reality tester - typically the hard option might be the only way out. The mediator might ask difficult questions which make parties think about positions they may be taking. The mediator gives the disputants' time to consult outside of the mediating team for possible solutions/options usually referred to as caucus.

- Resource expander - The mediator may assist parties with information they need to make informed decisions

- Educator of interest based bargaining as the mediator will educate the parties in negotiation

- Guardian of the process - ensures process is not abused or used to oppress

- Facilitator

- Deal maker

- Problem solver

- Transformer

- Evaluator

\section{Mediation process in promoting respectful and dignified care during childbirth}

Childbirth is a very stressful yet joyous moment for both the mother, family and the service provider. However, sometimes the mother, partner or relatives may feel that some of the events occurring around the labor and delivery process are not well-handled. Incidents of D\&A during childbirth should be discussed and the responsible parties held accountable in order to remedy the situation and prevent it from happening in the future. Mediation is one of the recommended methods that can be used to address D\&A.

\footnotetext{
${ }^{16}$ Christopher Moore, The Mediation Process: Practical Strategies for Resolving Conflict, (Jossey-Bass Publishers, San Francisco, 1996), p. 1433
} 
The advantages of mediation for patients/relatives include:

- Faster than a court process

- Less confrontational or adversarial

- Encourages creativity in searching for solutions

- Improves communication between parties

- Results in more durable solutions

- Less costly

- Flexible

- Less formal

- Party-controlled/driven

- Confidential

- Satisfying to the parties

The mediation process is voluntary and may be stopped at any time by a party or the mediator. Mediation can be structured in the following stages:

- Stage 1 - Introduction and the mediator's opening statement (climate setting)

- Stage 2 - Narration or presentation by the parties (story telling)

- Stage 3 - Determining interests

- Stage 4 - Setting out issues

- Stage 5 - Brainstorming options

- Stage 6 - Selecting durable options

- $\quad$ Stage 7 - Closure

\section{Stage One - Introduction}

- Introduction of mediator and parties

- Disclosure of mediator's qualifications

- Congratulating parties on choosing mediation

- The mediator should seek to establish and maintain trust and confidence

- Explanation of the mediation process/ground rules

- Disclaimer of bias and neutrality of mediator

- Signing of confidentiality agreement

\section{Stage Two - Presentation by the Parties}

- Parties provide perspective of dispute without interruption.

- This gives parties an opportunity to vent or express their anger and emotions

- Helps mediator to understand the parties and their interests

- Helps mediator to identify obstacles to resolutions 
- Provides an opportunity for parties to hear each other directly and to get the other's perspective

- The mediator needs to be an active listener and may ask questions for clarification

\section{Stage Three - Determining Interests}

- Mediator summarizes, clarifies, and confirms the interests of the disputants.

- Parties confirm the accuracy of the mediator's understanding of the disputants.

- Mediator may encourage parties to address each other directly, ask and answer questions, clarify misunderstandings, and offer acknowledgments.

\section{Stage Four - Setting Out Issues}

- Mediator helps disputants develop a list of issues

○ The objective is to help disputants focus on the specific items that must be resolved

- All issues that need to be resolved must be identified

- Mediator uses neutral language to frame issues in a way that promotes problem solving

\section{Stage Five - Brainstorming Options}

- Mediator encourages the disputants to generate and then select familiar and creative options

- Mediator and parties explore and discuss the pros and cons of each option

- Mediator guides disputants to focus on the problems and not on each other or the past

- Ideally, a workable option should come from the disputants themselves

\section{Stage Six - Selecting Durable Options/Closure}

- Mediator facilitates negotiations between the parties.

- Mediator helps the parties to pick realistic and viable options for resolution

- At this point, a caucus may be a useful technique

- The mediation will hopefully result in agreement

- If there is no agreement, the mediator should acknowledge progress made and explore prospects for further mediation 


\section{Application of mediation process in disrespect and abuse during childbirth}

Once a case is identified through a complaint and the parties involved choose to resolve it through mediation, the following should be done:

- Verify the facts through reports and listening to the parties involved. Such parties may include community strategy focal persons, members of community watch-dog groups, $\mathrm{CHWs}$, or service providers. Always record facts and obtain consent (see Appendix 5).

- Identify the mediators through whom the case can be heard. The disputants must feel comfortable with the mediators. Mediators may include:

- Members of facility management committee

- Society/community leaders/CHEWs

- Continuous quality improvement committees members,

- Representatives of professional association bodies

- District health management teams (DHMT)

- Health management teams (HMT)

- Identify a suitable venue, date and time

- Inform all the interested parties and the selected mediators and confirm their availability

- Once the disputants and mediator(s) converge at the venue, the mediator employs the mediation process as describe above 


\section{Role Play: The mediation process for resolving an incidence of physical abuse}

Directions: The facilitator selects three learners to perform the following roles: a skilled provider, a woman seeking redress for D\&A during childbirth at a health facility, and the mediator indentified to handle the incidence. The three participants should take a few minutes to read the background information provided and prepare for the role play. The observers in the group should also read the background information so that they can participate in small group discussion following the role play. The purpose of the role play is to provide an opportunity for learners to appreciate how an alternative dispute resolution mechanism might deal with D\&A incidents and promote accountability in reproductive rights.

\section{Participant Roles}

Provider: The provider is a midwife at the local health centre who has is accused of slapping a woman during a facility-based child birth.

Mr. X: Mr. X, 35 years-old, visits his wife gave birth the previous night in the facility to see their newborn baby and bring her a warm drink. He is rudely turned away by the watchman and the service provider on duty. He is accompanied by the village elder and $a$ friend.

The mediator: The mediator, Mr. Y, is a 45 year-old hospital administrator who is trained in mediation and is also a member of the health facility managemnt committee (HFMC). The facility management asked him to assist in resolving the issue.

Situation: Mrs X gave birth the previous night in the local facility. Her husband comes to visit to see their newborn baby and also bring her a warm drink. At the facility, he requests the service provider in the maternity ward to be allowed to see the baby and the mother but is rudely turned down since it is not yet the designated visiting time. A male watchman is asked by the service provider to escort him out of the ward. The watchman roughs the man up as he pushes him out of the ward premises.

From this case study, identify the forms of D\&A the husband was subjected to. State how Mr. X can seek redress for the actions. If mediation is the preferred avenue of redress, how can the mediation process be used to resolve the abuse?

The facilitator asks the participants to volunteer to demonstrate how mediation would be used in this case study using the steps describe above. 


\section{Focus of the role play}

The focus of the role play is the interaction between the service provider, Mr. X, the village elder, the watchman and the mediator?

The mediator should follow the subsequent stages (see the Alternative Dispute Resolution brief) to perform the session;

- Stage 1 - Introduction and the mediator's opening statement (climate setting)

- Stage 2 - Narration or presentation by the parties (story telling)

- Stage 3 - Determining interests

- Stage 4 - Setting out issues

- Stage 5 - Brainstorming options

- Stage 6 - Selecting sustainable options

- Stage 7 - Closure

\section{Discussion Questions:}

The facilitator should use the following questions to facilitate discussion after the role play:

1. How did the mediator approach Mr. X, his friend, the village elder, the watchman and the provider?

2. Did the mediator give the parties enough information about the role of a mediator? About the process of mediation? About maintaining confidentiality? About their rights to be heard equally?

3. How did the provider and Mr. $\mathrm{X}$ respond to the mediator?

4. How did the mediator demonstrate his/her objectivtity, non-coercion, control of the discussions during interactions between Mr. X, the watchman and the provider? And, the interactions with Mr. X's company?

5. Were the mediators's explanations and communication effective in resolving the incident? 


\section{SESSION 7:}

\section{Community's role in promoting respectful and}

\section{dignified childbirth}

\section{Learning objectives}

By the end of the session the participants will be able to:

1. Outline community members' role in promoting respectful maternity care.

2. State the community structures available for dealing with incidents of D\&A.

3. Demonstrate knowledge on identifying incidents of $D \& A$ at the community level.
Training materials

- Flipchart paper, markers, masking tape, sheets of paper or cards
Session

length:

60 Minutes

\section{Facilitator's instructions}

- Introduce the session by asking the participants to brainstorm on what they consider to be their role in promoting RMC

- Use a PowerPoint presentation to deliver the session content

- End the session with a group discussion on how to strengthen the existing community structures to respond to reports of D\&A incidents effectively

\section{Content}

\section{Community's Role in Promoting RMC}

Community members' role in promoting RMC includes:

- Identifying barriers that prevent them from receiving respectful care during childbirth in health facilities. These barriers include:

- Inadequate knowledge on labor and delivery procedures

- Failure to fulfill their rights and obligation

- Cultural beliefs and practices

- Myths and misconceptions

- Financial barriers (encourage birth planning and complication readiness plan) 
- Prevent D\&A by:

- Recognizing their right to quality care during childbirth in health facilities. Rights are entitlements that every human being possesses and is allowed to enjoy simply by virtue of being a human being

- Sensitize members on D\&A during maternity care which is a violation of women's basic rights.

- Educate and sensitizes the community on RMC

- Advocate for support of maternal health at all levels.

- Promote and maintain behavior change communication (BCC) in the community.

- Involve men in RMC and planning.

- Monitor and evaluate RMC services offered by facilities

- Proactively pursue information and education on good health practices including childbirth

- Respectfully demand good customer care during all kinds of services provided in health facilities including childbirth

- Resolve D\&A by:

- Report D\&A incidents as well as refer clients for professional counseling support- know who to report to and the counselor in your locality

- Encourage women that have experienced D\&A during childbirth to speak out and seek redress through mediation, counseling or other available resources

- Offer psycho-socio support to women and their families who experience D\&A during childbirth

- Establish or strengthen a clear linkage between the community and facilities to address $D \& A$

- Discuss mediation as an ADR.

- Mobilize community resources (money, material and human) to support initiatives that promote respectful and dignified childbirth such as legal and maternal health advocates, community watch dogs, HFMCs, community members / volunteers to work as mediators etc.

\section{Community Level Structures for dealing with D\&A}

Community members should be made aware of their rights and obligations to improve their response to D\&A. They should also be sensitized on the existing structures through which to claim their rights by reporting incidents of D\&A. 
These structures include:

- CHWs: These are volunteers trained by the $\mathrm{MOH}$ to offer basic health care and refer community members to formal health care services as appropriate.

- Health Facility Management Committees: These are established through an act of parliament and published through a gazette notice. They include representatives from communities and health facility management. The community members represent the community interest and the authority to make health management accountable for good health services.

- Legal aid officers and community watch dog's representatives: These are trained by the civil society on community's legal rights and have the mandate to educate the community on civil rights and assist them get redress if their rights are infringed on.

- Local administration: This includes chiefs, village and society leaders. They are charged with the responsibility of linking the community to other formal governments for any social issues including health and community welfare.

\section{Group Discussion}

1. Divide the participants into groups of 5 preferably from the same community unit/locality.

2. Ask participants to identify the local community structures that they can use to channel complaints on D\&A incidents from community members. Ask participants to discuss how the existing structures can be strengthened to respond effective to community reports on D\&A incidents.

3. Allow the participants to report this in plenary and guide the discussion on the best possible structures and how these can utilized. 


\section{SESSION 8:}

\section{Monitoring and data management in RMC}

\section{Learning objectives}

By the end of the session the participants will be able to:

1. Explain the role of data management in RMC interventions.

2. State the different tools and reports that would be used in the RMC intervention.

3. Describe the reporting structure for RMC interventions.

\section{Training}

materials

- Flipchart paper, markers, masking tape, sheets of paper or cards

\section{Facilitator's instructions}

1. Invite participants to share the different types of reports that they have interacted with.

2. For each report, ask them to explain the following:

- The purpose of the report

- The report structure

- The tools used in compiling the report

- The person who compiles the report

- The person to whom the report is sent

- The frequency of data collection and report writing

3. Using available slides, facilitate the session inviting participants to share their experiences as appropriate.

\section{Content}

\section{Record Keeping}

This refers to the systematic recording of information in standardized formats. It is also understood to mean the storage of such information.

Reports involve filling out, compiling specific information on data for use at a certain level e.g., ward/unit, facility, district, county, national and project level 


\section{Types of reports}

- Daily/monthly reports

- Incident reports e.g., maternal death, loss of baby, adverse event occurrence report

- Community meeting reports

- Maternal death review reports, among others.

\section{Importance of record keeping and data management}

Serves as a key planning tool in care at the ward/health facility level

They form the essential basis of monitoring, implementation and evaluation

It ensures transparency, accountability and follow-up where necessary

All activities to promote dignity in childbirth will be document by the community health workers and other volunteers and reported to the Community Health Extension Worker using the community monitoring (Appendix 6) 


\section{SESSION 9:}

\section{Develop action plans for sensitizing community members}

\section{on RMC}

Each group of participants will develop action plans

(see the template provided in Appendix 7)

\section{Action plans will be twofold;}

1). Working together with the community focal persons and/or CHEWs to initiate or strengthen the tested interventions discussed during the RMC workshop

2). Sensitizing community members through such existing avenues for public engagement on RMC, such as community dialogue days, Chief's Barazas, religious gatherings and women's groups among others

During these meetings trained CHWs will provide information on male involvement and birth planning, particularly escorting their wives to the hospital and saving small amounts of money throughout the pregnancy and seeking alternative health insurance schemes where they exist. The CHWS will also share information on existing channels to report incidents of $D \& A$ and call the community to action in creating some collaboration with HFMCs. All the $\mathrm{CHW}$ activities will be reported monthly to the respective $\mathrm{CHEW}$ or equivalent structure as part of their routine work.

\section{Action plans}

Ask participants to write down what is needed to implement each activity: (Refer to course content and add another context specific activity that may arise during the workshop)

- What needs to be done? By whom? By when?

- What resources are needed?

\section{Evaluation}

- What evidence indicates progress?

- How and when will evidence be gathered?

Allow each participant to work on her or his community unit work plan and share work plans with the plenary for discussion and input from other participants. 


\section{Implementing Action plans}

1. Request each participant to provide feedback /inform the local administration and community gate keepers of their action plans in order to enlist their support

2. Request the local administration and community gate keepers that they share information on any community level gatherings that might be relevant for RMC sensitization

3. Review/harmonize your planned activities with the relevant community-level gatherings

4. Use the community flipchart provided in the training session when offering updates to ensure standards are met for delivering the content. Refer to the tools provided in this RMC tool kit and share them with the community members

5. Evaluate knowledge gained by asking questions

6. Remember to make your presentation lively and very interactive

NOTE: You may break down you sensitization sessions into a series of 30 minutes-1 hour meetings based on the target group BUT make sure you plan other sessions to continue if necessary. 


\section{Bibliography}

1. Lale Say, Doris Chou, Alison Gemmill, Özge Tunçalp, Ann-Beth Moller, Jane Daniels, A Metin Gülmezoglu, Marleen Temmerman, Leontine Alkema. Global causes of maternal death: a WHO systematic analysis.

2. The Constitution of Kenya, 2010.

3. Warren. C, Njuki. Abuya. T, Ndwiga. C, Maingi. G, Serwanga. J, Mbehero. F, Muteti. L, Njeru. A, Karanja. J, Olenja J, Gitonga. L, Rakuom. C and Bellows B, Study protocol for promoting respectful maternity care initiative to assess, measure and design interventions to reduce disrespect and abuse during childbirth in Kenya, BMC Pregnancy and Childbirth 2013, 13:21 doi:10.1186/1471-2393-13-21: http://www.biomedcentral.com/1471-2393/13/21

4. WHO Infographic. 2014. "Saving Mothers Lives." http://www.who.int/reproductivehealth/publications/monitoring/infographic/en/

5. WHO, 2010. Using Human Rights for sexual and reproductive health: Improving legal and regulatory frameworks .Bulletin of the World Health Organization, Geneva

6. WHO, UNICEF, UNFPA and The World Bank estimates. Trends in maternal mortality: 1990 to 2010. Department of Reproductive Health and Research, World Health Organization, Avenue Appia 20, CH-1211 Geneva 27, Switzerland

7. Advancing women's rights in Kenya. Federation of Women Lawyers Kenya (FIDA Kenya). 2013

8. Failure to deliver: Violations of women's Human Rights in Kenyan Health Facilities. Center for Reproductive Rights and Federation of Women Lawyers Kenya. 2007

9. WHO. World Health Statistics 2014. Geneva, World Health Organization; 2014.

10. World Health Organization, UNICEF, UNFPA, The World Bank \& the United Nations Population Division. (2014).

11.Trends in Maternal Mortality: 1990 - 2013. Estimates by WHO, UNICEF, UNFPA, The World Bank and the United Nations Population Division. Geneva: WHO.

12. Respectful Maternity Care Advisory Council, White Ribbon Alliance for Safe Motherhood. (2011). Respectful maternity care: the universal rights of childbearing women. Washington, DC: WRA. Retrieved [18th June 2014]

13. Thaddeus S, Maine D: Too far to walk: maternal mortality in context. Soc Sci Med 1994, 38(8):1091-110

14. Bowser. $L$ and Hill. K., Exploring evidence for disrespect and abuse in facility-based childbirth: Report of a landscape analysis. . 2010, USAID

15. Plan. 2007. Because I Am a Girl: State of the World's Girls. London. http://www.un.org/womenwatch/osagi/conceptsandefinitions.htm 
16. Levine R., C.B. Lloyd, M. Greene, and C. Grown. 2008. Girls Count: A Global Investment \& Action Agenda. Reprint, 2009. Washington, D.C.: Center for Global Development

17.Universal Declaration of Human Rights. Geneva, United Nations, 1948.

18. WHO, 1946. Constitution of the World Health Organization. New York, World Health Organization, 1946.

19. OHCHR, 'Frequently Asked Questions on a Human Rights-Based Approach to Development Cooperation', 2006, p. 7, <www.ohchr.org/Documents/Publications/FAQen.pdf $>$.

20. Maternal mortality. May 2012; Available from: http://www.who.int/mediacentre/factsheets/fs348/en/index.html.

21. Maternal mortality. May 2012; Available from: http://www.who.int/mediacentre/factsheets/fs348/en/index.html 


\section{Appendix 1: Community TOTs Workshop Schedule}

\begin{tabular}{|c|c|c|}
\hline Time & Activity & Facilitator \\
\hline 08.30 & $\begin{array}{ll}\text { - } & \text { Participant Registration } \\
\text { - } & \text { Welcome and Introductions, } \\
\text { - } & \text { Logistics }\end{array}$ & $\begin{array}{l}\text { Community/Project } \\
\text { staff }\end{array}$ \\
\hline 08.45 & $\begin{array}{l}\text { - Expectations and norms } \\
\text { - Workshop objectives }\end{array}$ & \\
\hline 9.00 & $\begin{array}{l}\text { - Over view of maternal health } \\
\text { - Categories of disrespect and abuse during childbirth child } \\
\text { birth } \\
\text { - overview of Gender; Human Rights and Law ; }\end{array}$ & \\
\hline 10.30 & Tea Break & \\
\hline 11.00 & $\begin{array}{l}\text { Dealing with Disrespect and abuse } \\
\text { - Customer's Rights and Obligations } \\
\text { - Responsibilities of health service providers } \\
\text { - Responding to Clients/providers Rights - Maternity open } \\
\text { days } \\
\text { - Health Facility Management Committees/Boards } \\
\text { (HFMC/B) } \\
\text { - Quality Improvement Teams (QITs) Community } \\
\text { participation } \\
\text { - Community's role promoting in respect and dignified } \\
\text { childbirth }\end{array}$ & \\
\hline 01.00 & Lunch & \\
\hline 02.00 & $\begin{array}{l}\text { - Mediation as alternative dispute resolution } \\
\quad \text { Role play demonstration on conducting } \\
\text { mediation }\end{array}$ & \\
\hline 04.30 & Departure & \\
\hline
\end{tabular}


Appendix 2: Facts on maternal health status

\section{SAVING M(1)THERS' LIVES}

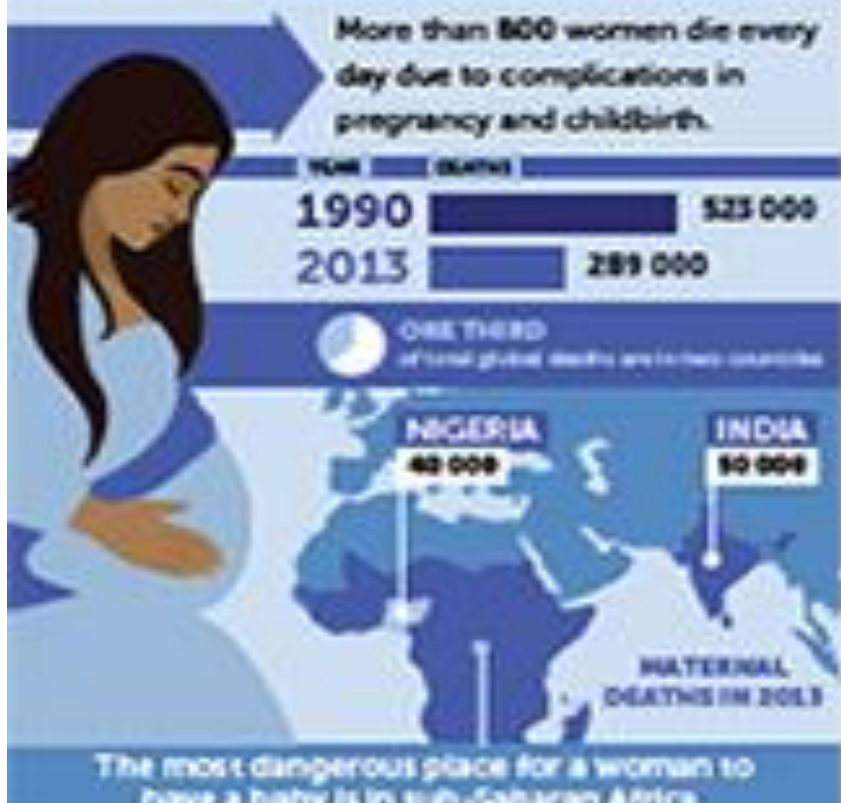

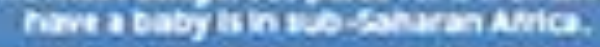

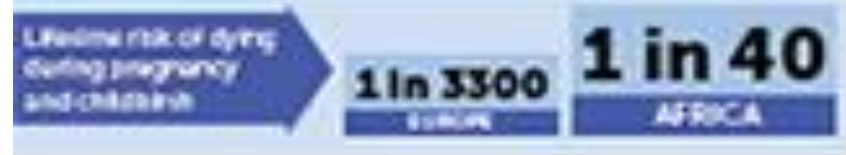

Part 1

\section{SAVING M(1)THERS' LIVES}

WHAT ARE PACCNANT WONEN DYNG FROM?

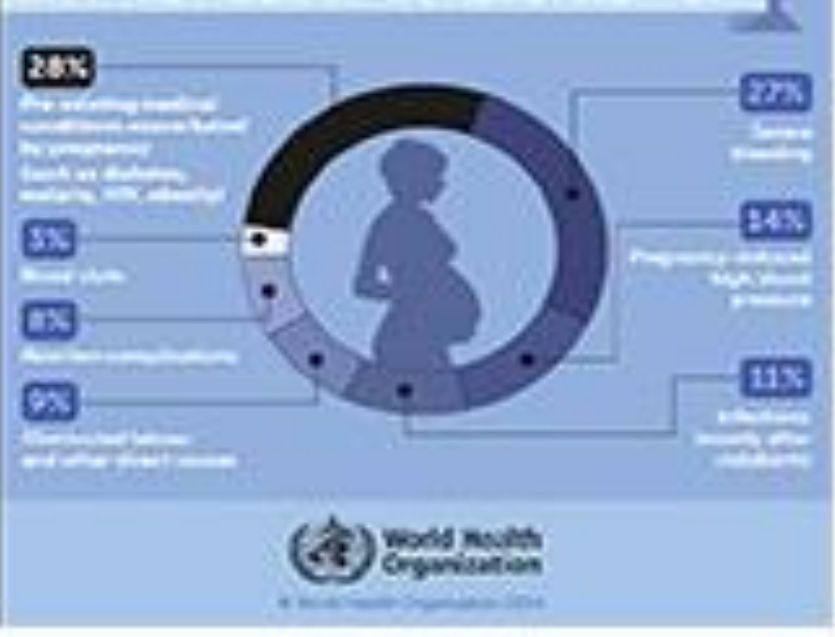

Part 2

\section{SAVING M(1)THERS' LIVES}

WHAT IS NEEOED TO SAVE MOAE UNES?
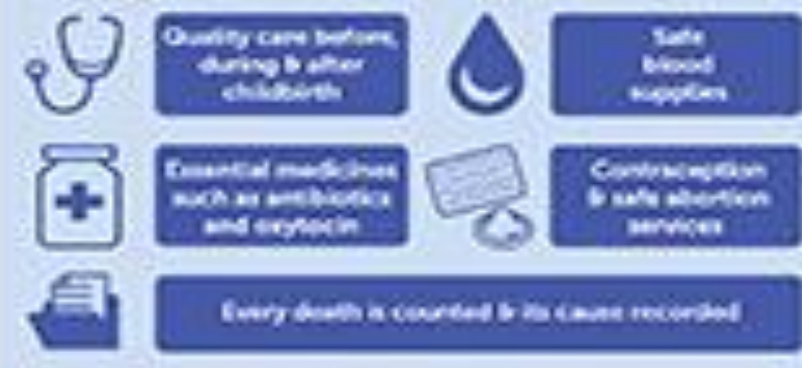

mavest? nevises:

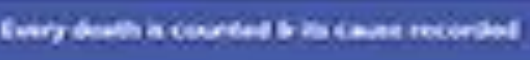

(t) Wors newh

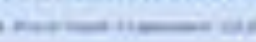

\section{Part 3}


In seeking and receiving maternity care before, during and after childibirth:

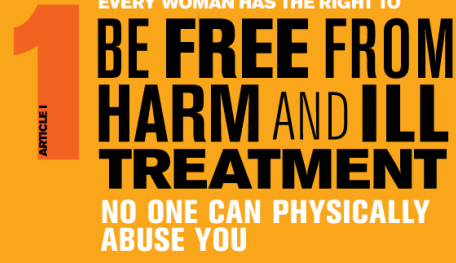

GVERYY WOMAN HAS THE RICHI TO

INFORMATION, INFORMED CONSENTANDREFUSAL, AND 19 125 UIUEC AND PREFERENGES, INCLUDING BOMPANONSHP DURING MATERNITY CARE NO ONE BAN FORBE YOU OR DO THNGS TO YOU WITHOU YOUR KNOWLEDGE AND BONSENT

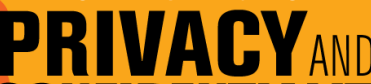 \\ BONFIDENIALIY \\ NO ONE BAN EXPOSE YOU OR \\ YOUR PERSONAL NFORMATION}

EVERY WOMAN HAS THE RIICHII TO

BE TREATED WITH

DIAN/AND

RES DET

NO ONE BAN HUMILIATE

OR VERBALLY ABUSE YOI

All rights are grounded in established international

heclaration of Human Rights; the Universal Declaration on Bioethics and Human Rights; the International Covenant on Economic, Social and Cultural Rights; the Internationa Covenant on Civil and Political Rights; the Convention on the Elimination of All Forms of Discrimination Against Women; the Declaration of the Elimination of Violence Against Women; the Report of the Office of the United Nations High Commissioner for Human Rights on preventable materna mortally and morbidity and human rights, and the United Nations Fourth World Conference on Women, Beijing. National instruments are also referenced if they make
Safe Motherhood is more than the prevention of death and disability... It is respect for every woman's humanity, feelings, choices, and preferences.

RESPECTFUL MATERNITY GARE: THE INIIERSA D OF CHIIDREARING WOMEN

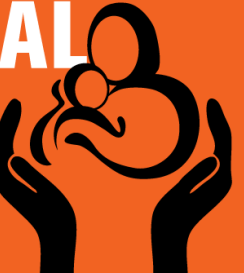

I EQUALITY, FREEDOM FROM DISCRIMINATION AND EQUITABLE CARE

NO ONE BAN DJSBRIMNATE BEBAISE OF SOMETHIT' THEY IO NOT IIKE ABOIT YUD

GIERYY WOMAN HAS THE RICHI TO HEALTHGARE

AND TO THE HIGHEST ATTAINABLE LEVEL OF HEALTH

NO ONE BAN PREVENT

YOU FROM GETINTE THE

MATERNITY GARE YOU NEEI

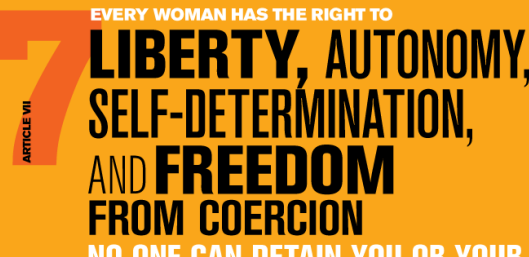

\section{NO ONE BAN DETAN YOU OR YOUR}

Disrespect and abuse during maternity care are a violation of women's basic human rights.

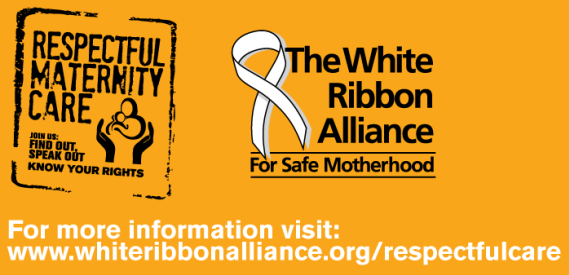


In seeking and receiving

maternity care before, during and after childhirth:

\section{BE FREE FROM \\ HARMANDILL TREATMENT \\ NO ONE BAN PHYSIBALYY \\ ABUSE YOU}

EVERYY WOMAN HAS THE RIGHI TO

INFORMATION, INFORMED

CONSENTANDREFUSAL,

ANDRESPEG FOR HER

GODES AND

PREFERENCES INCLUDING

COMPANIONSHIP

DURING MATERNITY CARE

NO ONE BAN FORBE YOU OR IO

THWGS TO YOU WITHOUT YOUR

KNOWLEHE AND GONSENT

\section{PRIVACY $_{\text {AND }}$ \\ RONFIDENTIALITY \\ NO ONE BAN EXPOSE YOU OR
YOUR PBRSONAL TNFORMATLN}

EVERY WOMAN HAS THE RICHII TO

BE TREATED WITH

DIANIIAND

RESPEQT

NO ONE BAN HUMILIATE

OR VERBALY ABUSE YOL

All rights are grounded in established international

human rights instruments, including the Universal Declaration of Human Rights; the Universal Declaration on Bioethics and Human Rights; the International Covenant

on Economic, Social and Cultural Rights; the International

Covenant on Civil and Political Rights; the Convention on the

the Decion of All Forms of Discrimination Against Wom

Woment the

Women; the Report of the Ofice of the United Nations High

Commissioner for Human Rights on preventable maternal

Nations Fourth World Conference on Women, Beijing.

National instruments are also referenced if they make specific mention of childbearing women.

Safe Motherhood is more than the prevention of death and disability...It is respect for every woman's humanit feelings, choices, and preferences.

RESPECTFUL MATERNITY GARE: THE INIVERSA RILITS OF CHIIDBEARING WOMEN
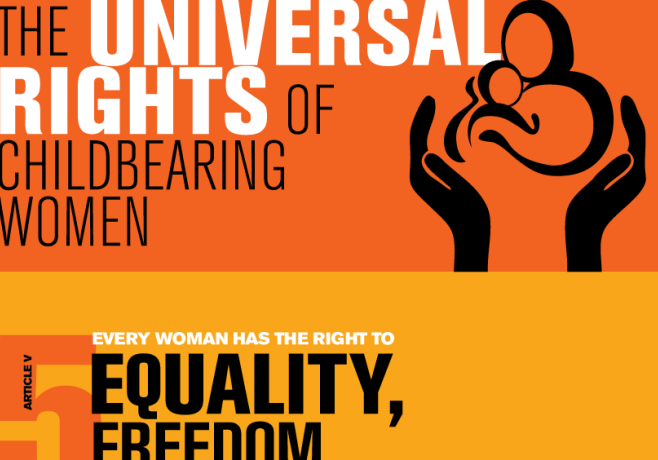
FREEDOM FROM DISCRIMINATION AND EQUITABLE CARE NO ONE BAN IISBRIMINATE BEBAUSE OF SOMETHNG THEY DO NOT LIKE ABOUT YOU

\section{HEALTHCARE}

AND TO THE HIGHEST

ATTAINABLE LEVEL

OF HEALTH

NO ONE BAN PREVENT

YOU FROM GEITNG THE

MATERNTY GARE YOU NEEI

\section{LIBERTY, AUTONOMY, SELF-DETERMINATION, ANDFREEDOM FROM COERCION \\ NO ONE BAN DEAAL YOU OR YOUR \\ BABY WhHOUT LEGAL AUHORIY}

Disrespect and abuse during maternity care are a violation of women's basic human rights.
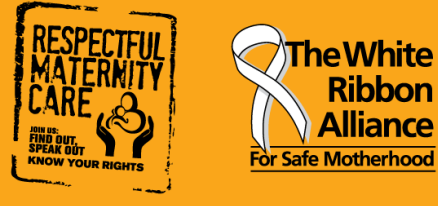

For more information visit:

WwW.Whiteribbonalliance.org/respectfulcare 


\section{Appendix 4: Community Brochure (Session 4)}

\section{ROLES OF FAMILIES AND COMMUNITIES}

- Farnilies and cornmunities should take action to address the barriers that prevents thern from receiving respectful care during childbirth in health facilities

- Farnilies and cornmunities need to recog nize their right to quality care during childbirth in health facilities. Rights are entitle ments to which a person inherently enjoys simply because she or he is a hurnan being

- As cornmunity mernbers we are the custorners to all kind of services provided in health facilities including childbirth

- The Ministry of Health Service Charter out lines the following custorners rights and obligations

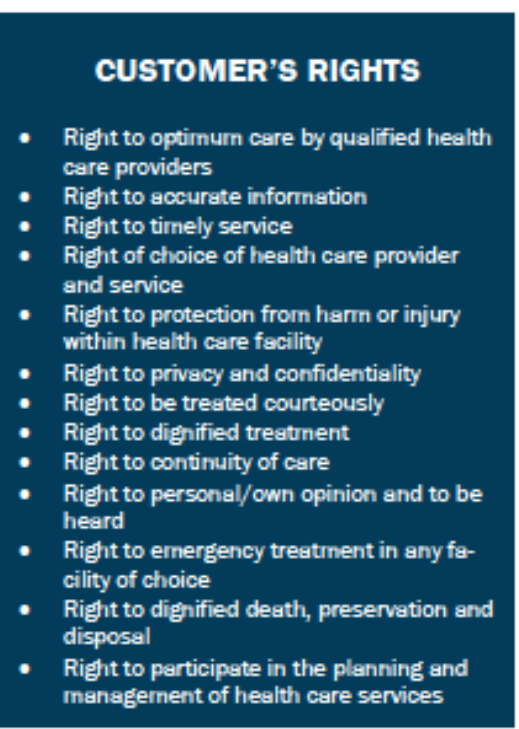

\section{CUSTOMER'S OBLIGATION}

Obligations are sornething you must do for moral or legal reasons, for your own benefit for others in the society:

- Engage in healthy lifestyle

- Seek treatunent promptly

- Seek information on illness and treatment

- Comply with treatunent and medical instructions

- Be courteous and respectful to health care providers

- Help cornbat corruption by reporting any corrupt practices, and refrain frorn seeking preferential treatment

- Enquire about the related costs of treatrnent and rehabilitation and agree on mode of payment

- Care for health records in your possession

- Respect the rights of other patients and health care providers

- Provide health care providers with relevant and accurate information for diagnosis, treatment, rehabilitation or counseling

- Protect and conserve health facilities

- Participate in managernent of health care services

- Foster partnership in service delivery

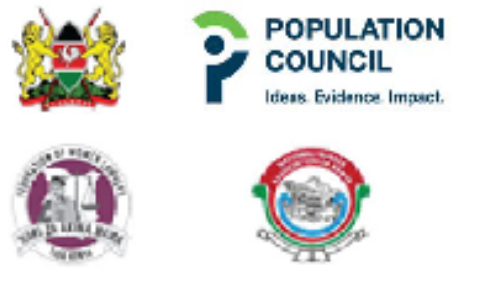

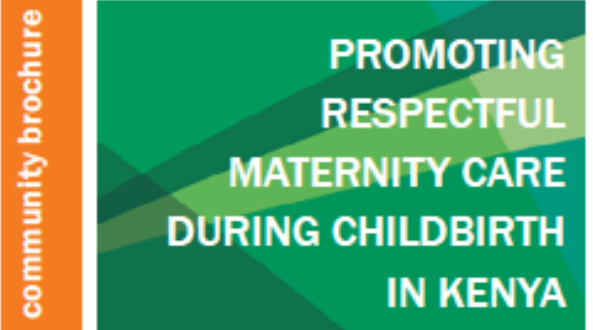

In Kenya, many mothers die due to problerns during pres nancy and childbirth. Mothers continue to deliver at horne, resulting in cornplications that put their lives and those of their unbom babies at risk.

Childbirth assisted by a skilled professional reduces the possibility of complications, and if complications occur while a mother is in a health facility, the health care provider can manage those complications effectively and prevent many deaths related to pregnancy and childbirth.

Only about 4 out of 10 wornen deliver at health facility, however there are number of reasons why wornen continwe to deliver at horne, including distance to facilities, and lack of transportation, lirnited awareness of the services gvailable, cost, wornen's role and their farnilies roles in deciding to seek care, cultural beliefs, and perceived friendliness of staff at facilities.

There is lirtle infornation on the interaction between wornen in labor and childbirth and their health care providers. There is need for cornenunities and providers to understand how this might affect wornen's decisions of where to deliver so they can work together to prornote respectful and dignified care during childbirth.

The Ministry of Health, Division of Reproductive Health and The Population Council, in collaboration with the Kenya Federation of Wornen Lawyers (FIDA) and the Netional Nurses Association of Kenya-Midwives' Chapter (NNAK-MC), worked together to prornote respectful ine ternity care at birth in health facilities and communities.

USAID TransLating 


\section{FINDINGS FROM THE COMMUNITY (2010)}

Plyysical abuse: Four percent of wornen exiting the facilities reported being physically abused. Both men and wornen feel that slapping, pushing or verbal abuse arnounts to disrespect and abuse. However some wornen felt that slapping by providers is sometimes done to ensure the wornen cooperate and focus on the birth.

Non-consented care: Four percent of wornen reported cases of non consented care. Lack of information regarding treatunent procedures were perceived as disrespectful by men while wornen felt that lack of explanation for medical procedures was abusive and disrespectful.

Non-confidential cares 7.4 percent of wornen interviewed felt that their privacy was violated. Specifically $3.9 \%$ wornen reported that providers did not keep information they had shared with thern confidential. Many communities perceive non confidential care as: i) exarnination, delivery and treatment that required undressing without curtains or partitions (ii) consultation conducted without privacy and (iii) group counseling and discussions where wornen are required to give all personal information in public.

Non-dignified care: Around one fifth of wornen were treated in a hurniliating way or felt disre spected, and 18 percent felt that providers used a tone or facial expression that made them fee uncornfortable. Cornmunities perceive non dignified care as: use of harsh words that suggest rudeness and disrespect, no assistance to carry baby soon after delivery; providers reprimand the client if she calls for help; cleaners and oth- er subordingte staff who are without any midwifery skills assist in delivery; when wornen are asked to undress in front of all other wornen in the labor wards and no gowns are not provided; sharing beds.

Discrimination: Cornmunity members feel that wornen at increased risk of discrimination are those that have five or more children; forget or lack the ANC card; are poor; are young wornen (teensge mothers); or are living with HIV.

Abandonment of care: 7.5 percent of wornen felt they were ignored when they asked for pain relief. Community perceive their women are abandoned when: providers ignore the clients or refuse to attend to the clients on time; providers lock thernselves in offices and do not respond; if there is no skilled personnel available wornen have to wait too long for cesarean section and no one cornes until cornplications develop; sorne wornen are left to deliver alone sorne wornen in severe pain are not given pain relief, some wornen end up giving birth on benches in adrnission roorn waiting for help.

Detention in facilities: Although detaining wornen in hospital for lack of funds to pay for treatment is illegal it still seerns to be a cornmon practice. Often detained wornen have to work in the facilities (washing utensils, toilets and washroom). Sornetimes mothers are not provided with beds and only the infant is fiven accornmodation and they are separated frorn their infants and only allowed to breastfeed the baby at fixed times.
WHAT ARE THE DRIVERS OF DISRESPECT AND ABUSE?: COMMUNITY PERSEPCTIVES

Health system factors:

- Inadequate infrastructure e.g. lack of beds, curtains and drugs at facilities

- Poor facility supervision and managennent; providers miss duties, and grave misconduct goes unpurished

- Poor peyrnent and high provider workload

- High cost of reproductive health services forces wornen to deliver at facilities of poorer quality thet are knoun to abuse wornen.

Community factors:

- Lack of clear understanding by cornmunities of legal mechanisms

- Perception arnong cornmunity mernbers that legal inechanisins and processes are expensive

- Sorne fornns of abuse have been nonnalized e.g. slapping, abusive practices are viewed as part of the process and ensuring the safely of inother and baby.

Personal factors:

- Limited individual and cornmunity empowernent can lead to lack of demend for quality services as 8 human right

- The waiver systern is perceived as a big favor, when wornen use it, they are cornpelled to accept services without questioning their provision

What health facility practices influence decisions on where to deliver?

- Inadequate knowledge on individual and communities rights to quality care during childbirth in health facilities

- Inadequate communication and linkage between the health facility management and providers and community members on issues related to facility besed childbirth

- Limited opportunities for communities to seek redress if women are unhappy with the treatment they receive

- Traditional beliefs, practices, customs and taboos make it difficult to discuss the issues around childbirth either with the health faciity staff or any form of authority at commu nity level. 


\title{
Appendix 5: D\&A incidence reporting and consent form
}

\author{
Community unit. \\ Facility attached to. \\ Month- \\ Year-
}

I. on this day. of yearconsent to my information being shared by Ministry of Health and the project partners namely FIDA, NNAK and Population Council for the purposes of record keeping and for any other relevant action pertaining promoting dignified and respectful care during child birth.

The information will not affect the services that I and my family or any other community member receives from any of the health facilities now and in future. I understand that that any information offered will be confidential and will be kept under key and lock dedicated to this study that only the study team can access.

I understand that if I agree to give the information or choose to end information giving at any time without penalty or loss of existing benefits to which I am entitled to. I am free to withdraw at any time without affecting my relationship with the $\mathrm{MOH}$ and the project partners.

I have read/received an explanation of the benefits and privacy of sharing my personal information. I agree to provide information on my own experience with regard to inhumane treatment during child birth. I understand that providing the information is voluntary.

\section{Your name-}

Your signature.

Telephone Number.

Location/community Unit.

Details of D\&A case 


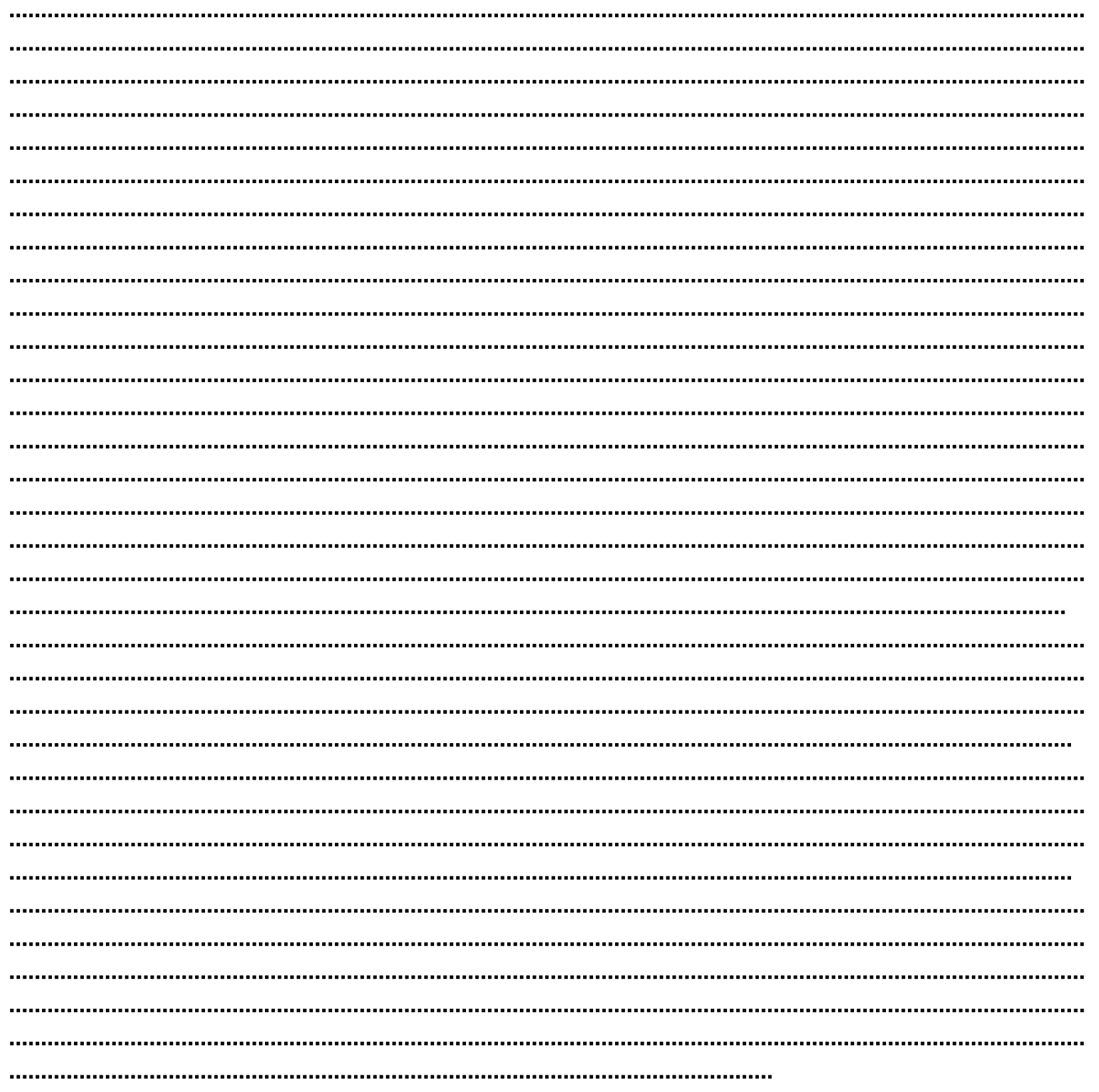

Reported by who



\section{Community Contact Person}

Telephone

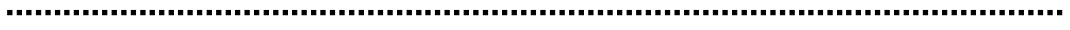

Signature

[............................

Date

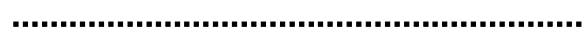




\section{Appendix 6: Monthly monitoring data form for community health workers (CHWs) and community health extension workers ${ }^{17}$ (CHEWs)}

Promoting dignified care to women during childbirth Name of CHW/CHEW. Phone number.

\begin{tabular}{|c|c|c|c|}
\hline IINDICATORS FOR COMMUNITY LEVEL & $\begin{array}{l}\text { No. of } \\
\text { females }\end{array}$ & $\begin{array}{l}\text { No. of } \\
\text { males }\end{array}$ & $\begin{array}{l}\text { Total } \\
\text { number }\end{array}$ \\
\hline \multicolumn{4}{|l|}{ 1. COMMUNITY-MEMBERS' TRAINING } \\
\hline \multicolumn{4}{|l|}{ a. No. of community dialogue days conducted to promote respectful childbirth this month. } \\
\hline \multicolumn{4}{|l|}{$\begin{array}{l}\text { b. No. of community members trained on promoting respectful childbirth during community } \\
\text { dialogue days this month. }\end{array}$} \\
\hline \multicolumn{4}{|l|}{$\begin{array}{l}\text { c. No. of community members actively involved in community activities to deal with D\&A during } \\
\text { this month (e.g., society leaders, community legal watchdogs). }\end{array}$} \\
\hline \multicolumn{4}{|l|}{$\begin{array}{l}\text { d. No. of D\&A cases reported by community members to health facility management committees } \\
\text { during this month. }\end{array}$} \\
\hline \multicolumn{4}{|l|}{$\begin{array}{l}\text { e. No. of D\&A cases resolved through mediation by community members and facility } \\
\text { management or staff participation during this month. }\end{array}$} \\
\hline \multicolumn{4}{|l|}{ f. No. of D\&A cases referred for counseling and mediation during this month. } \\
\hline \multicolumn{4}{|l|}{$\begin{array}{l}\text { g. No. of women referred or escorted from the community for facility-based childbirth during this } \\
\text { month. }\end{array}$} \\
\hline \multicolumn{4}{|l|}{ 2. MALE INVOLVEMENT IN BIRTH PLANNING } \\
\hline \multicolumn{4}{|l|}{ a. No. of male forums conducted to promote respectful childbirth this month. } \\
\hline \multicolumn{4}{|l|}{ b. No. of male partners trained on birth preparedness this month. } \\
\hline \multicolumn{4}{|l|}{ c. No. of male partners willing and involved in birth planning this month. } \\
\hline \multicolumn{4}{|l|}{ d. No. of male partners accompanying their partners/wives for ANC services this month. } \\
\hline \multicolumn{4}{|l|}{ e. No. of male partners accompanying their partners/wives for delivery services this month. } \\
\hline \multicolumn{4}{|l|}{$\begin{array}{l}\text { f. No. of male partners accompanying their partners/wives for postnatal cares services this } \\
\text { month }\end{array}$} \\
\hline \multicolumn{4}{|l|}{ g. No. of men championing rights and obligations to respectful childbirth this month } \\
\hline \multicolumn{4}{|l|}{ 3. YOUTH INVOLVEMENT IN PROMOTING DIGNIFIED CHILDBIRTH } \\
\hline \multicolumn{4}{|l|}{ h. No. of youth forums conducted this month to promote respectful childbirth. } \\
\hline \multicolumn{4}{|l|}{ i. No. of youths sensitized on promoting respectful childbirth during this month. } \\
\hline \multicolumn{4}{|l|}{$\begin{array}{l}\text { j. } \quad \text { No. of youths willing and involved in promoting respectful childbirth during this month. } \\
\text {. }\end{array}$} \\
\hline \multicolumn{4}{|l|}{ 4. WOMEN'S GROUP INVOLVEMENT IN PROMOTING DIGNIFIED CHILDBIRTH } \\
\hline \multicolumn{4}{|l|}{ a. $\quad$ No. of women's group forums conducted to promote respectful childbirth this month } \\
\hline \multicolumn{4}{|l|}{ b. No. of women sensitized on promoting respectful childbirth through women groups this month } \\
\hline $\begin{array}{l}\text { c. No. of women's groups championing rights to and obligations for respectful childbirth this } \\
\text { month }\end{array}$ & & & \\
\hline
\end{tabular}

Any comments-

-CHEWs contact

Telephone

Signature

Date-

17 This form is used by CHWs to keep records of the community-level activities. The community health extension workers then sum up the reports from their respective community units and send to the district/subcounty community focal person. 


\section{Appendix 7: Translating evidence in: action plans}

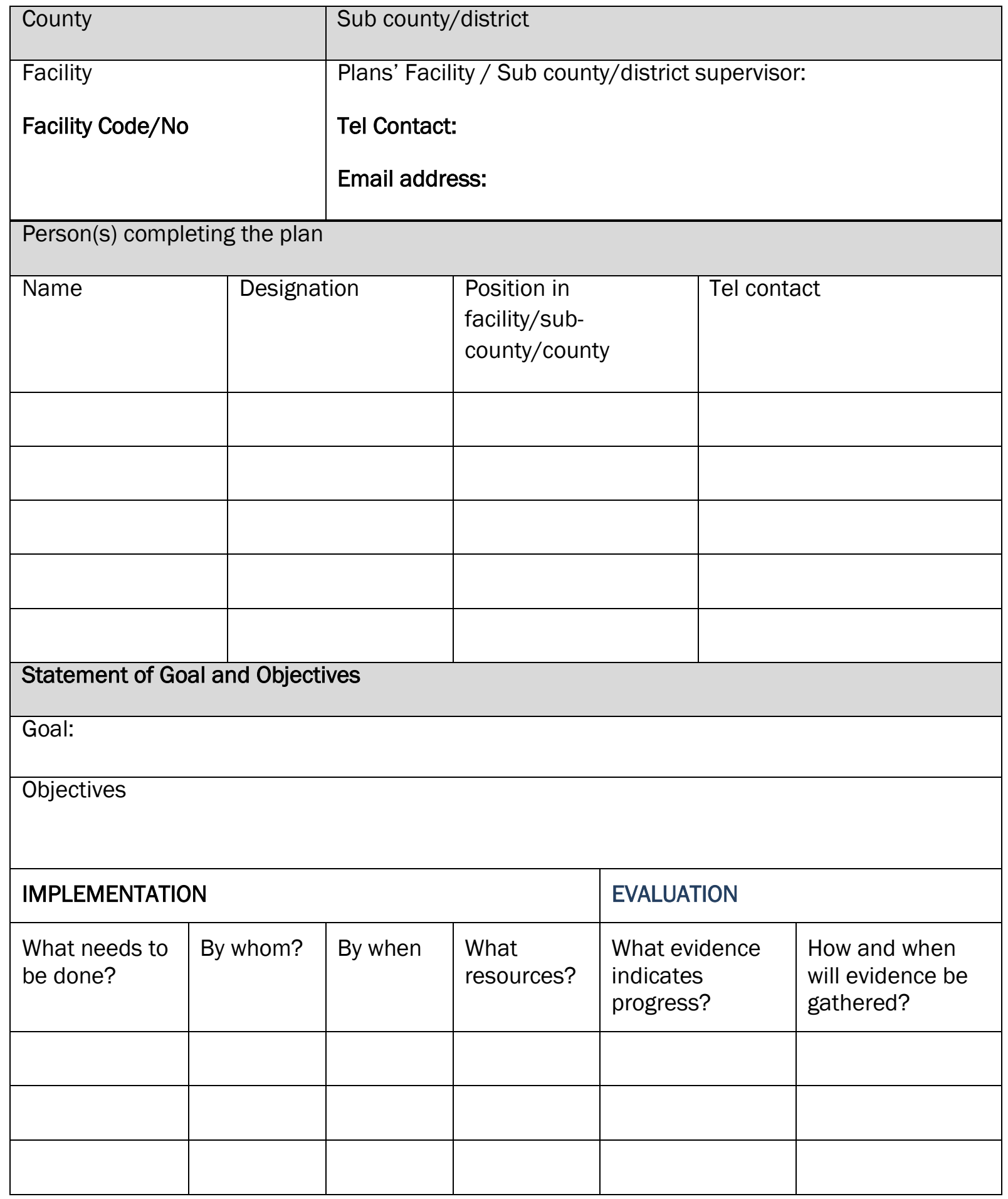

